\title{
What do Functional Synchronization Networks Indicate About Underlying Structure and System Dynamics? A network theory study in the islet.
}

Short title: Understanding Functional and Structural Networks

Jennifer K. Briggs ${ }^{1}$, Vira Kravets ${ }^{1,2}$, JaeAnn M. Dwulet ${ }^{1}$, Richard K. P. Benninger*1,2

1. Department of Bioengineering, University of Colorado Anschutz Medical Campus, Aurora, Denver Colorado

2. Barbara Davis Center for Childhood Diabetes, University of Colorado Anschutz Medical Campus, Aurora, Denver Colorado

* Corresponding author: richard.benninger@cuanschutz.edu 


\section{Abstract}

Network theory provides tools for quantifying communication within heterogeneous biological systems. Calcium-based imaging is a common technique used to analyze cellular dynamics and create functional networks. However, the use of functional networks in understanding the underlying biological structure, formed by physical connections, has not been well investigated. The islet of Langerhans is a biological system with relatively simple architecture that affords the opportunity for high-fidelity experimental and computation analysis, making it an ideal system to answer biological network theory-based questions. Here, we analyze both experimental and computational models of the islet to quantify the relationship between the gap junction structural network and functional synchronization networks. We show that functional networks poorly reflect gap junction structure. Instead, they indicate intrinsic factors driving excitability, such as cellular metabolism. This surprising finding provides a new interpretation of functional networks within biological systems.

\section{Teaser}

We use experimental and computational models to provide a new interpretation of intracellular synchronization in biological networks. 


\section{Introduction}

Our understanding of biological systems has greatly benefitted from the application of network theory (1), a set of analysis techniques used to quantify relationships between highly heterogeneous systems. In network analysis, a system is represented by its entities (called nodes) and the interactions between those entities (called edges). The topology and degree structure of the network (Table 1) provide information about the biological system, especially in the context of node influence and system perturbation. Network analysis has proved particularly useful in neuroscience, contributing to understanding Alzheimer's disease (2), seizure dynamics (3), and many other phenomena(4, 5).

To apply network theory tools to a biological system, one must decide whether to represent the network structurally or functionally $(4,5)$. Structural networks represent anatomical features: for example, in the brain, nodes correspond to either neurons or brain regions, and edges correspond to physical connections, such as synapses or axonal projections. In contrast, functional networks represent physiological dynamics. These networks are often generated by drawing edges between pairs of neurons or other cells that show highly correlated electrical dynamics. The relationship between functional and structural networks is poorly understood (5). Many network-informed biological studies utilize synchronization-based functional networks to make conclusions about a system because calcium-based imaging approaches are relatively common (6-8) and more accessible than directly identifying structural connection. These studies often assume that the functional network can be directly used to quantify pathological changes in the structural network; that is, a functional edge indicates a structural edge. However, this assumption has never been validated and is not correct for many systems $(4,5)$. This is particularly important if researchers plan to use functional network analysis to make conclusions about types of pathophysiology in which the structural network is disturbed, for example remodeling of a synapse, loss of gap junction connections, or accumulation of plaque.

Most biological systems are strikingly complex, making a complete network representation difficult. For example, the brain has on average 86.1 billion neurons and 84.6 billion "nonneuronal" cells (9). Additionally, the scaling of the brain is allometric, that is, non-proportional and non-linear across organism size (10) or substructures within the brain (11), making it difficult to extrapolate results between organisms or substructures. These facts can make neuroscience a challenging place for developing and validating network theory understanding in biological systems. More accessible models are needed to study the relationship between functional and structural networks.

The islets of Langerhans within the pancreas are comprised of insulin-producing $\beta$-cells that show dynamic hormone release patterns that are regulated by coordinated electrical dynamics (12-14). The release of insulin and glucagon from the islet is central to regulating the homeostasis of glucose and other nutrients. Dysfunction or death of insulin-producing $\beta$-cells underlies the development of diabetes. Islets are particularly tractable because they are a contained system that can be easily isolated, and they do not scale with organism size $(15,16)$. Therefore, the islet may be helpful in developing, validating, and testing network theory approaches, including quantifying the relationship between functional and structural networks. Within the islet, insulin-producing $\beta$-cells form a network of highly heterogenous, electrically active $\beta$-cells which are electrically coupled by connexin36 (Cx36) gap junctions $(13,17,18)$. This electrical coupling allows the $\beta$-cell network to synchronize its electrical dynamics and secrete insulin in discrete pulses (19), which are efficacious for the maintenance of glucose homeostasis (20-23). Interestingly, both type 1 and type 2 diabetes are preceded by the loss of this islet synchronization and disruption to Cx36 gap junction coupling $(20,24-27)$. Therefore, 
understanding the link between the islet structural network formed by gap junction channels, the functional network defined by $\mathrm{Ca}^{2+}$ activity patterns, and how these networks are disrupted in diabetes is highly relevant for understanding the progression of islet dysfunction in diabetes.

Studies have suggested that the functional $\beta$-cell network follows as a scale-free-like distribution (6), with a tendency toward a high clustering $(28,29)$. A scale-free distribution implies that there exists a subset of highly connected nodes, often called "hubs" $(4,30)$. By studying the distribution of the functional network, Johnston et al. and others (30-32) have suggested that $\beta$-cell hub cells have a greater than average influence on the islet and may be preferentially attacked by diabetic conditions, suggesting a possible mechanism behind the loss of pulsatile insulin secretion in diabetes. These $\beta$-cell hubs were also shown to have unique characteristics including high metabolic activity and depolarizing before and repolarizing after the rest of the islet $(30,33)$. However, electrophysiological experiments and computational studies suggest that it is not feasible for one cell or a small population of cells to have disproportionate influence over the Islet $(31,34,35)$. These studies have caused debate over the most accurate topological description of the islet network $(36,37)$.

One reason behind these seemingly contradicting results may be the inherent difference between the functional and structural networks within the islet. Electrophysiology can directly measure gap junction electrical coupling between individual cells by patch-clamp measurements (38). This allows for the description of individual nodes and their corresponding edges within the structural network. Alternatively, $\mathrm{Ca}^{2+}$ imaging-based studies provide signal dynamics of cells and their coordination across the system, based on which a functional network is constructed $(4,6,28)$. As such $\mathrm{Ca}^{2+}$ imaging reflects the functional network and does not provide direct measurements of gap junction connections between cells. Again, while the functional network emerges from the structural network, no evidence has been presented that the functional network can be directly used to infer the underlying structure, although this is often assumed to be the case. This detail is important for the interpretation of the network dynamics, such as the targeting of functionally connected cells, such as $\beta$-cell hubs, in diabetic conditions (30). If the functional network degree distribution from which these cells are derived is indicative of the underlying structural network distribution, (i.e. gap junction connectivity) then a direct attack to a $\beta$-cell hub will cause network breakdown because a physical, highly connected, and highly influential cell is removed. However, if the functional network degree distribution emerges from properties other than the structural network, then when a highly connected cell is removed, another cell of similar properties can take its place, as suggested in (34). To translate observations of synchronization into a deeper understanding of the $\beta$ cell network and its breakdown in diabetes, we must determine the causal factors for islet synchronization and the formation of the functional network. It is therefore essential that the direct relationship between structural and functional networks is quantified.

In this paper, we use novel experimental and computational techniques to investigate the relationship between the structural and functional networks over different spatial scales. We refer to the functional network as the network formed by connecting cells that show highly synchronized $\mathrm{Ca}^{2+}$-dynamics, and the structural network as the network formed by physical gap junction connections. First, we investigate how gap junction coupling influences the synchronization of $\mathrm{Ca}^{2+}$ dynamics at a cellular level. That is, if two cells are synchronized in the functional network, what can we infer about their gap junction coupling in the structural network, or other properties? To answer this question, we combined computational modeling results with consecutive $\mathrm{Ca}^{2+}$ imaging and quantification of gap junction permeability via measurements of dye transfer kinetics (39) in order to compare structural and functional connections at a cellular scale. Second, we investigate the influence of gap junction coupling on the functional network at the islet level by perturbing gap junction coupling 
computationally and via Cx36 knock out mice. We investigated how the coupling conductance throughout the islet influences network topology via quantifying network parameters such as clustering coefficient and small world-ness. Finally, we investigated how another intrinsic property of the cells, their metabolic activity, influences the functional islet network. We again combined computational modeling results with consecutive $\mathrm{Ca}^{2+}$ imaging and real-time quantification of cellular metabolic activity. We draw unexpected conclusions about the relationship between intrinsic cellular properties and the functional network. These results provide fresh insight into how to interpret the relationship between gap junction connections in the structural network, intrinsic cellular properties and cellular synchronization in the functional network. 


\section{Results:}

Cellular metabolism is more influential than gap junction coupling in determining highly synchronized cells in a simulated $\beta$-cell network.

Accurately analyzing cellular characteristics within a network, including intrinsic factors underlying cellular excitability and electrical coupling via gap junction channels (i.e., the structural network), is highly non-trivial to perform experimentally. Thus, to investigate the relationships between functional and structural networks, we first analyzed a simulated $\beta$-cell network. We used a $1000 \beta$-cell electrophysiological computational model described previously $(31,40,41)$, which included heterogeneity in multiple factors underlying cellular excitability and in gap junction electrical coupling (Figure 1a).

We first performed functional network analysis on the simulated intracellular free $\mathrm{Ca}^{2+}\left(\left[\mathrm{Ca}^{2+}\right]\right)$ dynamics. Two cells were considered synchronized if their Pearson correlation coefficient $\left(R_{i j}\right)$ was greater than a threshold $R_{t h}$. We then generated normalized degree distribution of the functional network which shows the presence of many cells with low degree and a few cells with very high degree in the five simulated islets (Figure 1b). Highly synchronized cells, referred to as $\beta$-cell hubs, were identified within the functional network as any cell with greater than $60 \%$ of the network edges, as set forth in (30). Within a simulated islet, multiple such $\beta$ cell hubs were present (Figure 1c). These $\beta$-cell hubs tended to depolarize before and repolarize after the islet average (Figure 1d), in agreement with previous studies (30). We next analyzed the properties of these highly connected $\beta$-cell hubs. Critical factors which influence $\beta$-cell excitability include the rate of glucose metabolism to generate ATP $\left(k_{\text {glyc }}\right)$ and the activity of ATP-sensitive $\mathrm{K}^{+}\left(\mathrm{K}_{\text {ATP }}\right)$ channels. $\beta$-cell hubs had a significantly higher rate of glucose metabolism $\left(k_{\text {glyc }}\right)$ than non-hubs $(p \leq 0.0001)$ (Figure 1e) but not significantly different in their maximum $\mathrm{K}_{\mathrm{ATP}}$ conductance ( $\left.\mathrm{g}_{\text {KATP }}\right)(p=0.18$ ) (Figure 1f). Interestingly, $\beta$-cell hubs had only a slightly higher gap junction conductance than non-hubs $(p=0.032)$ (Figure 19). These results indicate that both metabolic activity and gap junction coupling are correlated with high cellular synchronization, with rate of metabolic activity having the much stronger correlation.

\section{Elevated cellular metabolic activity, but not elevated gap junction permeability is observed experimentally in highly connected cells}

To test whether the properties of highly connected cells that we identified within the simulated network occur within islets of Langerhans, we performed time-lapse imaging of $\left[\mathrm{Ca}^{2+}\right]$ within islets isolated from Mip-CreER; LSL-GCamp6s mice that express GCamP6s specifically in $\beta$-cells ( $\beta$-GCamP6s mice, see methods). At elevated glucose, islet $\beta$-cells showed synchronous oscillations in $\left[\mathrm{Ca}^{2+}\right]$ (Figure 2a,b). We performed Pearson-based functional network analysis on these $\left[\mathrm{Ca}^{2+}\right]$ time-courses (see methods) (Figure $\mathbf{2 c}$ ) and generated a normalized degree distribution that describes this experimentally-derived functional network (Figure 2d), which again reflects a large number of low degree cells and few high degree cells.

To test whether cellular metabolic activity differed between highly synchronized cells we performed two-photon excitation of $\mathrm{NAD}(\mathrm{P}) \mathrm{H}$ autofluorescence of $\beta$-cells in conjunction with time-lapse imaging of $\mathrm{Ca}^{2+}$ dynamics at 2- and 11-mM glucose levels (Figure 2e). The metabolic activity of individual cells in the islet was calculated as a difference between the $\mathrm{NAD}(\mathrm{P}) \mathrm{H}$ autofluorescence level at high glucose compared to low glucose $\left(N A D(P) H_{11-2}\right)$. This was adjusted by the mean change in autofluorescence across all cells in the islet $(N A D(P) H$ 
11av-2av). This metric was equal to 0 if the $\mathrm{NAD}(\mathrm{P}) \mathrm{H}$ of a cell was the same as the islet-average, $>0$ if a cell was more metabolically active, and $<0$ if a cell was less metabolically active. The $N A D(P) H$ response to glucose elevation decreased as the cell's normalized degree decreased (Figure $\mathbf{2 f}$ ). This indicates that highly synchronized cells are more metabolically active, as measured by $\mathrm{NAD}(\mathrm{P}) \mathrm{H}$ autofluorescence, in agreement with findings from simulated islets. Furthermore, the $\mathrm{NAD}(\mathrm{P}) \mathrm{H}$ response trended lower in cells that were functionally disconnected, as indicated by $\mathrm{Ca}^{2+}$ oscillations lacking synchronization with any other cells, compared to the NAD(P)H response in connected cells (Figure $\mathbf{2 g}$ ).

While it is not possible to experimentally measure the strength of every gap junction connection across the islet, fluorescence recovery after photobleaching (FRAP) measurements of dye transfer kinetics can measure the gap junction permeability within the islet with cellular resolution (39). We performed FRAP measurements of gap junction permeability using a Cx36 gap-junction-permeable tracer Rhodamine-123 in conjunction with $\mathrm{Ca}^{2+}$ time-lapse imaging of GCamP6s, to map cellular gap junction connections in the same cell layer as functional connections are calculated (Figure $\mathbf{2} \mathbf{h}, \mathbf{i}$ ). We found that the rate of recovery, which assesses gap junction permeability, lacked any trend with $\mathrm{Ca}^{2+}$ synchronization (Figure $\mathbf{2 j}$ ). Therefore, synchronization was not strongly correlated with gap junction permeability, as measured by FRAP, which is consistent with findings from the simulated islet.

At the cellular scale, the functional network cannot be used to infer the structural gap junction network.

Our findings so far indicate that highly synchronized cells within the functional network correlate more strongly with cell intrinsic metabolic properties such as metabolic rate and activity, than with gap junction electrical connections. We next investigated the relationship between edges derived from the functional network and edges within the structural network. For a given cell, we observed a low degree of overlap between functional network edges and structural network edges (Figure 3a). The low degree of overlap between structural and function networks was observed irrespective of the cell's degree of synchronization, that is considering highly connected $\beta$-cell hubs, cells with average synchronization, or cells with low synchronization (Figure 3a). The probability that two cells were synchronized in the functional network given that they shared a gap junction in the structural network was $\operatorname{Pr}(S y n c \mid G J)=0.39$ (Figure 3b). This indicates that less than half of cell pairs that are electrically coupled by gap junction connections are functionally coupled. Further, the alternative probability of a structural edge given functional edge was $\operatorname{Pr}(G J \mid S y n c)=0.04$ (Figure 3b). This indicates that very few cells that are functionally coupled are directly connected by gap junction connections. As such cells that are structurally connected via gap junction connections and cells that are functionally connected via synchronized $\left[\mathrm{Ca}^{2+}\right]$ dynamics are two distinct groups with little overlap $(\operatorname{Pr}($ both $)=0.2)$ (Figure 3c).

To investigate the previous finding that high synchronization is strongly correlated with the cellular metabolic activity, we then created two new networks: i) in which we drew an edge between cells if they had similar rates of glucose metabolism ( $\mathrm{k}_{\mathrm{glyc}}$ ), the rate limited step in glucose metabolism (Figure $\mathbf{3 d}$ ) or ii) in which we drew an edge between cells if they had higher than rates of glucose metabolism. For both networks there was no difference in the probability of a connection within the functional network given similar (i) or high (ii) rate of glucose metabolism (Figure $3 \mathbf{3 e}$ ). Therefore, it is equally likely that two cells will have synchronized $\mathrm{Ca}^{2+}$ oscillations whether they have similar rate of glucose metabolism or whether they both have higher than average rate of glucose metabolism. The alternative probability of similar rate of glucose metabolism (i) or 
elevated rate of glucose metabolism (ii) given a functional edge was significantly higher than that of structural connections $(p=0.024)$ for both networks (Figure $3 \mathbf{f})$. Therefore, if two cells have synchronized $\mathrm{Ca}^{2+}$ oscillations, they are more likely to show either similar metabolic activity or have higher than average metabolic activity, compared to the two cells that are gap junction coupled. This is further indicated by the increased overlap between the $\mathrm{Ca}^{2+}$ synchronization-derived functional network and the metabolic activity-derived network (Figure 3g).

Hence, in agreement with experimental findings, these results further indicate that metabolic activity, not gap junction connections, is a greater driving factor for cells to show high $\mathrm{Ca}^{2+}$ synchronization and thus influence the functional network.

\section{Elevated cellular rate of glucose metabolism is a greater driver of long-range functional connections.}

We noted that in the simulated islet model, gap junction connections only exist between highly proximal cells, in accordance with the islet cytoarchitecture. However, there was no distance constraint on $\left[\mathrm{Ca}^{2+}\right]$ oscillation synchronization, or metabolic connections (Figure 4a). We therefore asked whether long-range functional connections could be predicted by a series of highly conductive gap junction connections. To assess this, we weighted the structural network by gap junction conductance and calculated the path which maximized conductance between synchronized and non-synchronized cells (Figure 4b) (see methods: shortest weighted path length). This was then expressed as the total $g_{\text {coup }}$ for different distances of cell separation. In some cases, the total $g_{\text {coup }}$ between a given cell and a cell it was synchronized with was greater than that between the given cell and a non-synchronized cell of the same cell distance, (Figure $\mathbf{4 b}$ top) while in other cases the nonsynchronized cell showed a higher total $\mathrm{g}_{\text {coup }}$ (Figure $\mathbf{4 b}$ bottom). Further, the probability distributions of total conductance for synchronized cells highly overlapped with those for non-synchronized cells. This was observed for cells that were directly gap junction coupled (Figure 4c) and cells that showed longer-range functional connections (Figure 4d). We compared the total conductance between all cells irrespective of separation distance by normalizing the total conductance by separation distance. The normalized total conductance was slightly less for non-synchronized cells than for synchronized cells (Figure 4e), although still with substantial overlap (Figure 4c,d). Thus, long-range functional connections traverse cells that are connected on average by slightly higher gap junction conductance. However, the substantial overlap in total conductance between synchronized and non-synchronized connections is consistent with the minor influence of gap junction conductance in driving high synchronization between cells.

To examine how cellular rate of glucose metabolism influenced long-range functional connections, we repeated this procedure but weighted graph edges by $k_{\text {glyc }}$ rather than coupling conductance ( $g_{\text {coup }}$ ). This was expressed as the total $k_{\text {glyc }}$, for different distances of cell separation. Again, the probability distributions of the total $k_{\text {glyc }}$ for synchronized cells were highly overlapping with that for non-synchronized cells; both for cells that were directly gap junction coupled (Figure 4f) and cells that showed longer-range functional connections (Figure $\mathbf{4 g}$ ). The total rate of glucose metabolism, normalized by separation distance, was significantly less for nonsynchronized cells than for synchronized cells (Figure $4 \mathrm{~h}$ ), with little overlap. Thus, long-range functional connections on average traverse cells with higher rates of glucose metabolism.

We then analyzed the total conductance or total cellular metabolic rate for different separation distances compared between synchronized cells or non-synchronized cells. Cumulative distribution functions 
(CDFs) reveal the small difference in total conductance (Supplemental 1) or total rate of glucose metabolism (Supplemental 2) for each cell separation distance. Synchronized cells had significantly higher total cellular metabolic rate than non-synchronized cells for distances 1 to 5 cells apart, with very high level of significance. Conversely gap junction conductance was significantly higher for only synchronized cells 2, 4, 5, 6, and 7 distances apart, with a lower level of significance. Thus, cells pairs with similar metabolic rate can strongly influence longer-range function connections up to distances of 5 cells apart. In contrast, cells with higher gap junction conductance have less influence over longer-range functional connections but can influence these connections over slightly longer distances.

Individual gap junction connections cannot be predicted by the functional network with correlated gap junction conductance and metabolic activity.

It has previously been suggested that cells with highly synchronized $\mathrm{Ca}^{2+}$ oscillations possess both elevated metabolic activity (in agreement with our findings, Figure 2) and high levels of gap junction conductance (unlike what we see in our experiment, Figure 2$)(30,32)$. To address the possibility that cells with high metabolic activity may also have higher levels of gap junction conductance, we simulated an islet in which the rate of glucose metabolism positively correlated with gap junction conductance (Figure 5a), similar to the distribution presented in (31), and generated the functional network (Figure 5b). There was no difference in the average degree of the functional network (i.e. average islet synchronization) between the random distribution (Figure 1) and this proportional distribution (Figure 5c). Highly synchronized $\beta$-cell hubs had a significantly higher metabolic rate compared to non-hubs (Figure $\mathbf{5 d}$ ). In this simulated islet the gap junction conductance was also significantly higher in hubs (Figure 5e), as expected given that cells with higher $\mathrm{k}_{\text {glyc }}$ are programmed to have higher $\mathrm{g}_{\text {coup. }}$ Again, there was no significant difference in $\mathrm{g}_{\text {KATP }}$ between $\beta$-cell hubs and non-hubs (Figure $\mathbf{5 f}$ ). As with a normal distribution, the probability that two cells were synchronized in the functional network given that they shared a gap junction connection in the structural network $(\operatorname{Pr}(S y n c \mid G J)=.303)$ was much greater than the alternative probability of a structural edge given functional edge $(\operatorname{Pr}(G J \mid S y n c)=0.027)$ (Figure 5g) Importantly, both $\operatorname{Pr}($ Sync $\mid G J)$ and $\operatorname{Pr}(G J \mid S y n c)$ were smaller than the equivalent probabilities determined when $\mathrm{k}_{\mathrm{glyc}}$ and $\mathrm{g}_{\text {coup }}$ are not correlated (Figure $\mathbf{5 g}$, Figure $\mathbf{3 b}$ ). Therefore, the structural network still could not be effectively derived from the functional network (Figure $\mathbf{5 g}, \mathbf{h}$ ). We calculated the total $\mathrm{g}_{\text {coup }}$ between synchronized and nonsynchronized cells along weighted networks using the previous methodology. The total gcoup was significantly higher for cell distances from 1-9 and 14 cells apart (Figure 5i). Therefore, when $\mathrm{g}_{\text {coup }}$ is proportional to $\mathrm{k}_{\text {glyc, }}$ synchronization is more predictive of long-range connections mediated by high gap junction conductance than of individual gap junction connections.

\section{Modulating the islet-wide structural network in Cx36 knockout islets}

So far, we have analyzed the relationship between the functional and structural islet networks at a cellular resolution, where we observed that $\mathrm{Ca}^{2+}$ synchronization was poorly predictive of cells having gap junction connections. We next investigated the extent to which disruptions to the gap junction structural network affected the $\mathrm{Ca}^{2+}$ functional network. As we showed earlier, longer range functional edges (synchronized cell pairs) >4 cells apart on average had slightly higher gap junction conductance compared to non-synchronized cell 
pairs. It is also well established that changes to gap junction conductance affects the emergent $\mathrm{Ca}^{2+}$ dynamics across the islet (13). Therefore, we used experimental and computational models to investigate how changes in the structural network influence functional network topology at an islet-wide resolution. Given that Cx36 forms the gap junction channels that enable electrical communication between $\beta$-cells, reducing or eliminating $\mathrm{Cx} 36$ will remove edges from the structural network. We performed functional network analysis on time-courses of oscillatory $\left[\mathrm{Ca}^{2+}\right]$ dynamics in islets with reduced or absent $\mathrm{Cx} 36$ : from wild-type mice $\left(\mathrm{C} \times 36^{+/+}\right)$, heterozygous Cx36 knockout mice $\left(\mathrm{C} \times 36^{+/}, \sim 50 \% \mathrm{~g}_{\text {coup }}\right.$ ) and homozygous Cx36 knockout mice (Cx36 ${ }^{-/}, \sim 0 \% \mathrm{~g}_{\text {coup }}$ ) (13) (Figure $6 a-c)$. Figure $6 \mathbf{c}$ shows representative degree distributions of the functional networks corresponding to the islets shown in Figure 6a. Average histograms of the degree distribution for all islets are presented in Supplemental 3a. As expected, the functional degree distributions for both $\mathrm{C} \times 36^{+/-}$islets and $\mathrm{C} \times 36^{-/}$islets were increasingly right-skewed (Figure $\mathbf{6 c}$, Supplemental 3a), indicating a decrease in the average islet synchronization. Heterozygous ${\mathrm{C} \times 36^{+-}}^{+-}$islets demonstrated decreased $\left[\mathrm{Ca}^{2+}\right.$ oscillation synchronization compared to wild-type $\mathrm{C} \times 36^{+/+}$islets (Figure 6d, Figure 6a-c middle vs. left, Supplemental 3b); whereas homozygous $\mathrm{C} \times 36^{-/-}$ demonstrated further decreased $\left[\mathrm{Ca}^{2+}\right]$ oscillation synchronization compared to both wild-type $\mathrm{C} \times 36^{+/+}$islets (Figure 6d, Figure 6a-c right vs. left, Supplemental 3b) and $\mathrm{C} \times 36^{+/-}$islets (Figure 6d, Figure 6a-c right vs. middle, Supplemental 3b). Consistent with this, substantially more cells in Cx36 $6^{+/-}$islets ( $74 \%$ of cells) and $\mathrm{Cx} 36^{-/-}$islets ( $93 \%$ of cells) were not synchronized to any other cell in the islet, compared to in $\mathrm{Cx} 36^{+/+}$islets (40\% of cells) (Figure 6e). Islets were of similar size ranges in each case (Supplemental 3c).

We next quantified the functional network characteristics upon the knockout of $\mathrm{C} \times 36$ that disrupted the structural network, including clustering coefficient, shortest path length, global efficiency (Table 1). To determine how likely it was for the observations to be caused by randomly formed connections, we compared each metric to the metric determined from multiple random networks created with the same number of nodes, edges, and degree of connectivity as the network of interest $(6,42,43)$. An example random graph is shown in Table 1. The relative overlap between the network characteristics from the islets of interest with those of a random network describes the likelihood that the functional network of the islets could be created by random chance. In all cases, these functional network characteristics did not show any significant mouse to mouse variability (Supplemental 4).

Clustering coefficient $\left(C_{\text {avg }}\right)$ quantifies the percent of nodes connected to a given node that are also connected to each other (Table 1). It therefore reflects local properties of the network. However, it is important to note here that "local" does not indicate the physical proximity of the cells but rather the topological placement of the cell with respect to its edges in the functional network. A high clustering coefficient in the functional network would indicate that cells tend to synchronize with other cells that share some attribute. Random graphs have low clustering because the edge connections are not dependent on cell attributes (42). If the physical gap junctions are the attribute that gives the functional network a high clustering coefficient, then reducing gap junction coupling should result in a clustering coefficient close to zero and be completely explained by the random graph. The clustering coefficient of the functional networks decreased significantly as gap junction coupling decreased, being significantly lower in $\mathrm{Cx} 36^{+/-}$islets and $\mathrm{C} \times 36^{-/}$islets compared to $\mathrm{C} \times 36^{+/+}$islets (Figure 6f). However, for all islets, the clustering coefficient of the islet network was greater than that of a random network $C_{\text {avg }}>C_{\text {rand }}$ (Figure 6f). Thus, in agreement with previous results, this finding suggests that something other than the gap junction structural network contributes to local properties of the functional network topology. 
Average shortest path length $\left(L_{a v g}\right)$ is defined as the average smallest number of nodes required to traverse between any cell pair (Table 1). It, therefore, represents the global characteristics of the network. A short path length indicates that one could traverse nodes in a network in a small number of steps compared to the islet size (42). In other words, a short path length indicates that cells can communicate efficiently across long distances. A random network or a regular network with a few edges randomly moved (Table 1) will have a small shortest path length. The normalized shortest path length increased significantly as gap junction coupling decreased, and was significantly higher in $\mathrm{C} \times 36^{+/-}$islets and $\mathrm{C} \times 36^{-/-}$islets compared to $\mathrm{C} \times 36^{+/+}$islets (Figure $6 \mathrm{~g}$ ). For $\mathrm{C}_{3} 36^{+/+}$islets, the measured shortest path length was much greater than that of a random network $\left(L_{\text {avg }}>\right.$ $\left.L_{\text {rand }}\right)$. However, as gap junction coupling decreased, the measured shortest path length showed a larger intersection with that of a random network: for $\mathrm{C}_{3} 6^{-/}$islets all measured data points could be explained by random chance $\left(L_{\text {avg }} \approx L_{\text {rand }}\right.$ ). This finding suggests that gap junction structural network contributes to global, long-range properties of the functional network topology. Global efficiency, which has previously been used to describe islet networks (6), is related to the inverse of the shortest path length (Table 1). Global efficiency significantly decreased with decreased gap junction coupling (Figure $6 \mathrm{~h}$ ). Similar to path length, as gap junction coupling decreased, the measured global efficiency showed a larger intersection with that of a random network.

We then calculated the extent to which the functional network appeared to have small-world qualities. A small-world network is one that exhibits the high clustering of a regular network and the high efficiency (short path length) of a random network (Table 1). Therefore, a small-word functional network is highly efficient to traverse (along functional edges), but cells still tend to synchronize will other cells of similar attributes. The small world-ness (S) of a network, has been presented in previous network-based studies using two techniques, $\left(S_{E}\right)$ and $\left(S_{L}\right)(16,31) . S_{E}$ and $S_{L}$ both trended larger as gap junction coupling decreased (Figure $6 \mathbf{i}$ and Supplemental 3d), with $S_{E}>1$ for all islets. However, the uncertainty in both $S_{E}$ and $S_{L}$ significantly increased as gap junction coupling decreased. An alternative metric has been presented to analyze small world-ness specifically for disconnected networks, such as the networks in our study where a significant proportion of cells lacked functional edges (44). Local efficiency reveals how efficient the communication is between neighbors of a node when that node is removed. Thus if both global efficiency $E_{\text {global }}$ and local efficiency $E_{\text {local }}$ are large, the network has small world qualities (44). Further, because this technique does not utilize random networks, it does not have any uncertainty. There was a significant decrease in local efficiency with reduced gap junction coupling, being significantly lower in $\mathrm{C} \times 36^{+-}$islets and $\mathrm{C} \times 36^{-/}$islets compared to $\mathrm{C} \times 36^{+/+}$islets (Figure $6 \mathbf{j}$ ). Therefore, using this more appropriate calculation for small world-ness, as gap junction coupling decreases and both global and local efficiency decrease, the small world-ness of the functional network decreases. This indicates that reducing gap junction coupling decreases (but does not completely abolish) the communication efficiency of the islet. However, the fact that the random networks cannot explain the clustering of $\mathrm{C} \times 36^{-1}$ indicates that other attributes are driving differences in cellular synchronization.

Finally, to quantify the relationship between physical location and $\left[\mathrm{Ca}^{2+}\right]$ oscillation synchronization, we calculated the ratio between the average distance separating synchronized cells and the average distance separating all cells in the islet $\left(D=\frac{D_{\text {sync }}}{D_{\text {all }}}\right)$. If this ratio is less than one, it would indicate that cells tended to synchronize preferentially based on location. The average distance between synchronized cells compared to islet average was less than one for all but one $\mathrm{C} 36^{-1-}$ mouse (Figure 6k) and there was no significant difference between the three islet genotypes. This further suggests that the physical gap junction coupling is not the only factor driving the synchronization of oscillatory $\left[\mathrm{Ca}^{2+}\right]$ dynamics. 


\section{Altering the gap junction structural network in the computational model agrees with experiments}

Next, we investigated the effects of gap junction coupling on the functional network topology in our computational model by altering the average coupling conductance $\left(\mathrm{g}_{\text {coup }}\right)$. As expected, islets with reduced average $\mathrm{g}_{\text {coup }}$ showed reduced $\left[\mathrm{Ca}^{2+}\right]$ oscillation synchronization: simulated islets with average $\mathrm{g}_{\text {coup }}=0.12 n S$ had higher synchronization than simulated islets with average $\mathrm{g}_{\text {coup }}=0.06 n S$ or $0.03 n S$ (Figure 7a). Similarly, following functional network analysis, the total number of functional network edges decreased as gap junction coupling was decreased (Figure $\mathbf{7 a , b}$ ). The probability that two cells were connected in the functional network given that they were gap junction coupled (connected in the structural network, $\operatorname{Pr}(S y n c \mid G J)$ ) decreased significantly as gap junction coupling was decreased (Figure 7c). This indicates that as the gap junction conductance decreases and the network becomes more sparse, the probability of having two cells that are synchronized given they have a gap junction decreases. Similarly, the probability that two cells were connected in the functional network given the cells had similar rates of glucose metabolism decreased as gap junction coupling decreased (Figure 7d). Conversely, the probability of a gap junction connection given that two cells were synchronized in the functional network $(\operatorname{Pr}(G J \mid S y n c))$ increased as gap junction coupling decreased (Figure 7e). The probability of two cells showing similar rates of glucose metabolism given that two cells were connected in the functional network also increased as gap junction coupling decreased (Figure 7f) and showed higher probabilities than that for $\operatorname{Pr}(S y n c \mid G J)$ in each case. This indicates that as gap junction coupling decreases, it is more likely to find both a gap junction connection given synchronization and metabolically similar cells given synchronization. However, this is not because the overlap between the two networks is larger but because the number of synchronized cells is smaller (Figure $7 \mathbf{b}$ ).

We then quantified the functional network characteristics upon reduced gap junction conductance and compared these characteristics with experimentally determined network characteristics. The clustering coefficient $C_{\text {avg }}$ progressively decreased with decreasing gap junction conductance (Figure 7g). However, the clustering coefficient from the simulated islets was always substantially greater than that determined from a random network, with no overlap (Figure $\mathbf{7 g}$ ). Global efficiency also progressively decreased with decreased gap junction conductance (Figure $\mathbf{7 h}$ ). The global efficiency from the simulated islets was always less than that determined from a random network with no overlap (Figure 7h). These trends are similar to that of the experiments but the lack of overlap between random and measured global efficiency is more pronounced. Also similar to our experimental observations, the small world-ness parameter $\left(S_{E}\right)$ increased as gap junction conductance decreased. Again, the uncertainty in the calculation of $S_{E}$ greatly increased, indicating that this parameter is not reliable for highly sparse networks (Figure 7i). Also similar to our experimental observations the local efficiency decreased with gap junction conductance (Figure 7j). The decreases in both global efficiency and local efficiency with decreasing gap junction conductance indicate that the network strays away from small world properties as gap junction conductance decreases. This follows our experimental observations.

Finally, we analyzed the sensitivity of these probabilities and network quantities to the correlation threshold $R_{t h}$. By nature of the method, as the threshold was increased, the number of cells considered synchronized substantially decreased (Supplemental 5a, b). The probability that two cells were gap junction coupled given that they were connected in the functional network greatly increased with increasing correlation threshold (Supplemental $5 c$ ), such that when $R_{t h}=0.99995, \operatorname{Pr}(G J \mid S y n c) \approx 0.5$. This was not due to an 
bioRxiv preprint doi: https://doi.org/10.1101/2022.02.06.479331; this version posted February 9, 2022. The copyright holder for this preprint (which was not certified by peer review) is the author/funder. All rights reserved. No reuse allowed without permission.

increasing "overlap" between the functional network and structural network, but rather the decrease in the size of the functional network sample space (Supplemental $\mathbf{5 d}$ ). 


\section{Discussion:}

The primary aim of this study was to investigate what functional networks can indicate about the structure of a biological system. Functional networks are often created by thresholding a Pearson correlation coefficient between calcium dynamics of cell pairs, to draw edges between the most synchronized cells. It is reasonably assumed that this high synchronization indicates some similarity between the two cells. However, the exact nature of this similarity has not been well quantified. Many studies make the explicit or implicit assumption that high synchronization indicates a functional connection, such as a synapse or gap junction connection between the cells. However, this has not been firmly demonstrated.

Calcium-based imaging is a common technique used to analyze cellular dynamics, create functional networks and identify cell subpopulations. For this reason, most network-informed biological studies utilize synchronization-based functional networks to make conclusions about a system. This approach has yielded tremendous insight into how different subpopulations of cells can contribute to system dynamics $(6,28,30,31$, $34,45)$. However, when discussing the loss of synchronization due to cell death or disruption in signaling, such as the case for many diseases, it is changes in the structural network (e.g., gap junctions, synapses, accumulation of plaque) that cause dysfunction. Therefore, the relationship between the structural and functional network must be quantified if any conclusions about structural network dynamics are to be made via functional network analysis. The islet of Langerhans is a closed biological system with relatively simple architecture that affords the opportunity for high fidelity experimental and computation analysis, making it an ideal system to answer biological network theory-based questions. In this study, we ask three main questions. First, what does the functional network indicate about the structural network? Particularly, can we accurately identify gap junction connections based on cellular synchronization, as some studies have alluded to? Second, how does the functional network change when the structural network is altered? Third, what cellular properties other than structural connections are reflected in the functional network?

To make our quantification of the structural and functional networks more robust, we used both experimental and computational techniques to investigate these network-based questions. Computational modeling is beneficial because it allows us to carefully adjust and extract the exact system parameters and quantify the entire three-dimensional network without noise. Experiments can then be used to verify model findings and trends on real-world data. This kind of joint analysis is important for robust, repeatable conclusions.

\section{$\mathrm{Ca}^{2+}$-based Functional Network Cannot Be Used to Infer Gap Junction Structural Network}

Conditional probabilities directly quantify the relationship between the structural and functional networks, and the accuracy of the assumption that synchronization can be used to infer gap junctions. The probability of synchronization given gap junction connection $(\operatorname{Pr}(\operatorname{Sync} \mid G J))$ directly addresses the question of whether cells connected by gap junction are always highly synchronized. Unexpectedly, only $\sim 40 \%$ of gap junction connected cells were considered synchronized by functional network analysis. While it is a well-known fact that gap junctions are required for islet-wide synchronization (13), this finding suggests that other factors besides just physical connections contribute to the high synchronization of individual cell pairs. The probability of a gap junction given a synchronized cell pair $(\operatorname{Pr}(\mathrm{GJ} \mid$ Sync)) addresses the assumption that synchronization can be used to infer gap junctions. If this probability is high, then functional network analysis can be used to directly infer the 
underlying gap junction structure. We found that $\operatorname{Pr}(\operatorname{Sync} \mid \mathrm{GJ})$ for five simulated islets was $<5 \%$, indicating that synchronization absolutely does not imply a direct gap junction connection.

We also investigated whether a long-range functionally synchronized cell pair indicates a chain of highly electrically-coupled cells. While the electrical communication between $\beta$-cells is not uni-directional, this analysis allows us to detect even the most minute influence of gap junction paths on $\mathrm{Ca}^{2+}$ synchronization. While synchronized cells did have a lower gap junction resistance (or higher conductance) than non-synchronized cells, the strong overlap in distributions indicates that it is inaccurate to conclude that a strongly synchronized longrange pair of cells will always have a higher gap junction conductance than a less strongly synchronized pair.

Finally, we looked to validate our results experimentally. Fluorescence recovery after photobleaching (FRAP) (46) provides a measurement for gap junction permeability. To our knowledge, this is the first time measurements of gap junction permeability have been compared with functional connectivity measurements with cellular resolution. By analyzing islets using both $\mathrm{Ca}^{2+}$-based functional analysis and FRAP, our data showed that highly synchronized cells do not have higher gap junction permeability. These experimental findings strongly support our computational findings that gap junctions are not the primary distinguishing factor in determining variations in cellular synchronization. Therefore, questions involving the structural network, such as network resiliency to physical removal of nodes or edges, cannot be directly answered by studying the functional network topology

Even in a well-defined and simple structural architecture such as the islet, it is highly inaccurate to assume that synchronized cells are structurally connected, even when the structural network is expanded to chains of gap junction connections. At best, the functional network is loosely correlated with structure at the cellular level. In some ways, this finding is rather obvious as gap junctions can only form between highly proximal cells, whereas synchronization is not bound by distance. The more surprising part of this finding is that gap junctions do not guarantee synchronization, as previously thought (29). While structural connections do provide the pathway for a coupling current, we know that it is the individual cell's membrane conductance that determines the actual coupling current strength (31). In (31), we show that metabolic activity, intrinsic frequency, and cell state are highly influential in determining the magnitude and direction of the coupling current. As such, intrinsic cell factors not only control the individual cell's oscillatory dynamics but also how much that cell communicates with its structurally connected neighbors. We discuss this further below.

\section{Alteration in Structure Influences Functional Network Topology}

While the functional network cannot be linearly mapped to the structural network, previous studies show that there is a relationship between the two $(13,47)$. Genetically knocking out the $\mathrm{Cx} 36$ gap junction protein in mice islets allows us to "remove" edges from the structural network. Previous studies have shown that Cx36 deficiency in mice leads to slower calcium waves (13), loss of calcium oscillations and synchronization and loss of pulsatile insulin secretion (18).

Local and Global Functional Network Topology: In the computational model, neither clustering coefficient which reflects local properties of the functional network, nor global efficiency which reflects global properties of the

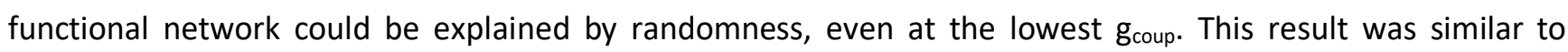
experimental findings which reflect a single 2-dimensional plane whereas the computational model reflects the entire 3-dimensional network. According to experiments by Watts and Strogatz (43), only the most ordered 
networks will show zero overlap with randomness between the clustering and efficiency statistics. Our results are unexpected because if gap junctions were solely responsible for variations in islet synchronization, a decrease in gap junction coupling would cause the functional network to appear more random. Instead, this indicates that $\beta$-cells are preferentially, not randomly, synchronized even in the presence of very low gap junction coupling. This synchronization must be explained by other intrinsic cellular properties of the $\beta$-cells, which supports our previous claim that gap junctions are not the only factor important in determining cellular synchronization. The high clustering coefficient found experimentally in Cx36 knockout islets and computationally with low $\mathrm{g}_{\text {coup }}$ indicates that cells tend to be functionally connected (i.e. synchronized) independent of gap junctions. These results again contribute to the evidence that gap junction connections are not the only driver of synchronization. Of note, the partial overlap between global efficiency between $\mathrm{Cx} 36$ knockout islets and a random network suggests that gap junctions play some role in maintaining long-range functional connections. This is consistent with our computational measurements that show slightly elevated gap junction conductance in long-range ( $>4$ cells) connections between synchronized cells compared to nonsynchronized cells. Further, the significant decrease in both clustering coefficient and global efficiency of the functional network with decreasing Cx36 expression and $g_{\text {coup }}$ indicates that changes in the gap junction structural network do alter the functional network topology, which may have implications into the islet pathophysiology.

Small World-ness: The "Small World-ness" of a network has important implications for network structure, such as indicating efficient signal propagation and high ability to synchronize (6). A small world network, as defined in (43), has characteristics of both a regular and random network, with a high global efficiency and high clustering coefficient. Since these values are relative, multiple techniques have been developed to quantify the network's small world-ness. It should be noted that the functional network of the islet formed by the synchronization of $\mathrm{Ca}^{2+}$ oscillations is not technically a small-world network because there are multiple cells within the islet that are completely disconnected, making the average path length infinite $(48,49)$. Even though these cells are "disconnected," they still contribute to the network dynamics and thus should not be ignored. Regardless, it is interesting to compare the extent to which the $\mathrm{Ca}^{2+}$ oscillation synchronization acts as a small world. We utilized three different techniques to calculate small world-ness. The first two techniques, presented in $(6,43)$, compare network statistics with a random network: in a small world network the clustering coefficient should be much greater than the random network, but the global efficiency or average path length should be similar to the random network. As such, $\frac{\frac{C}{C_{\text {rand }}}}{E}$ or $\frac{\frac{C}{E_{\text {rand }}}}{L}$ should be greater than 1 in a small-world network. Using these techniques, all the scenarios were considered "small world" for computational and experimental measurements. However, the uncertainty strongly increased as coupling decreased particularly in the computational measurements which consider more cells. 
As the network becomes sparser, the placement of each edge has much greater influence, and the probability that $C_{\text {rand }}=0$ or $E_{\text {rand }}=0$ increases greatly, which causes the calculation to explode. These calculations are therefore not reliable for highly sparse networks. To analyze the small world-ness without the confounding influence network sparsity, we used a third technique(44), which claims that small-world networks should have a high global and high local efficiency. Using this technique, our results show that, as coupling decreased, the functional network became less small world-like. This implies that as structural gap junction connections are removed, the islet loses efficient signal propagation and high ability to synchronize. This decreased functional small worldness likely contributes to the lack of islet coordination and pulsatile insulin in diseases such as diabetes, where gap junction coupling has been shown to decrease $(26,27,50)$.

\section{The Functional Network is a Better Indicator of Cellular Metabolism than of Structure}

The data we present show that gap junctions cannot completely explain variations in cellular synchronization or network topology, indicating that some other property is contributing to functional synchronization. Our computational and experimental results show the existence of a subpopulation of highly synchronized cells within the islet, known as $\beta$-cell hubs $(30,51)$, which are characterized by a higher than average metabolic activity and the electrical signature of depolarizing before and repolarizing after the rest of the islet. The simulated $\beta$-cell hubs emerge from the network with the assumption that rate of glucose metabolism and gap junction coupling is independent of one another. Therefore, dependency between rate of glucose metabolism and gap junction coupling is not required for the existence of $\beta$-cell hubs. Interestingly, rate of glucose metabolism is associated with $\beta$-cell hubs more strongly than structural gap junction coupling. Computational studies showed a low correlation between gap junction coupling and synchronization, while experiments showed no trend. In contrast, experimental studies showed a clear correlation between synchronization (as defined by the cell's degree in the functional network) and metabolic activity (reflected by NAD(P)H florescence). Semi-quantitative immunofluorescence has indicated that $\beta$-cell hubs may show elevated metabolic activity due to elevated GK protein levels (30). However, to our knowledge real-time quantification of metabolic activity has not been correlated to cellular synchronization. Further, the probability that two cells had high average metabolism or similar average metabolism given they were synchronized was significantly larger than the probability of gap junctions given they were synchronized. In other words, when choosing two synchronized cells from the functional network, it is more accurate to assume that these cells are metabolically similar or have a higher metabolically activity rather than being preferentially coupled by gap junctions. We also found that longer-range cellular synchronization was more strongly correlated with the metabolic rate for up to 5 cells separation. These findings indicate that short to medium range synchronization is more reflective of metabolic activity while long-range synchronization is more reflective of slightly higher conduction by gap junction connections.

These findings make physical sense because, in the case of electrically active cells such as neurons or cells in the islet of Langerhans, gap junctions are not the primary factor driving electrical activity. Cell metabolism is responsible for driving electrical activity and $\mathrm{Ca}^{2+}$ elevations, while gap junctions facilitate ion passage between cells to synchronize electrical oscillations. Previously we showed that cells that are preferentially activated by optogenetic ChR2 stimulation were more metabolically active by $\mathrm{NAD}(\mathrm{P}) \mathrm{H}$ autofluorescence, but not preferentially gap junction coupled (52). Furthermore, we have shown that gap junctions have a larger role in repolarizing the cells back to resting membrane potential compared to depolarizing cells to an elevated 
membrane potential (31); whereas metabolic activity is more influential in driving cellular depolarization. Additionally, in a completely uncoupled network, cells with identical frequencies will still be synchronized. Since the metabolic activity is highly influential in a cell's oscillatory frequency, it makes sense that metabolic activity would be strongly influential in determining functional edges.

\section{Broader implications}

We have shown evidence that the functional network of the islet of Langerhans is influenced by its underlying structure but is more reflective of intrinsic cellular metabolic activity than gap junction connections. Studies have shown that the hyper-polarization of highly synchronized $\beta$-cell hubs disproportionately disrupts islet calcium dynamics, but the actual removal of hubs does not $(31,34)$. Our new perspective that $\beta$-cell hubs are uniquely defined by metabolic activity rather than gap junction coupling helps explain these results because the primary responsibility of $\beta$-cell hubs is not to keep the cells synchronized (as a highly connected cell in a structural smallworld network would), but rather to drive islet oscillation through metabolic activity. This new perspective should also be utilized when studying calcium dynamics, with the new understanding that synchronization can give insight into cellular properties that drive excitability of the cell, such as the metabolic activity of $\beta$-cells. Further, perturbations in metabolism, such as metabolic stress that occurs in diabetes, may have a significant influence on the synchronization of the islet. While this study was conducted on experimental and computational representations of the islets of Langerhans, we suggest that these findings can be carefully extrapolated to larger systems.

\section{Potential Limitations}

The most obvious limitation of this study, as for any computational study, is that computational models do not perfectly reflect reality. We partially ameliorate this limitation through experimental studies which agree well with the computational models. However, the greater strength in this particular use of the computational islet model, is that all our results are internally derived. That is, even if the computational model is not reflective of the experimental islet, the functional and structural networks were obtained from the same model, so the relationship between them is not dependent on the models' ability to reflect islet dynamics (though we have shown that it does well). This fact also allows our results to translate to any oscillatory network with similar characteristics.

The choice of threshold when creating the functional network is incredibly influential in the results (Supplemental 5) and should be carefully considered in any use of synchronization to create the functional network. We carefully picked our threshold to match that of the prior experimental results. The computational threshold was very high $\left(R_{t h}=0.9995\right)$ because, unlike experiments, the computational model had no noise, so the synchronization was more acute. Additionally, in the Cx36 KO model we analyze only electrical oscillations, whose frequency ranges from 1-2 minutes (53). A similar analysis should eventually be done considering slower metabolic oscillations and factoring in the (currently unknown) mechanism by which these metabolic oscillations may be synchronized. We also assume that gap junction connections between cells are constant throughout the time of analysis. Finally, the islet also contains $\alpha, \delta, \gamma$, and other cell types which have been shown to influence $\beta$-cell dynamics through various mechanisms (54-56). This study only analyzes $\beta$-cells which is the common 
practice among other network studies which we compare to $(6,30,32)$. However, we cannot exclude long-range structural projections from $\delta$ cells (57) and that $\delta$ cells may be gap junction coupled (58). In the future, network analysis should be applied to include other cell types as it could give valuable insight how their interactions can shape the overall islet response to nutrient changes.

\section{Conclusions:}

In this study, we investigate the relationship between the synchronization-based functional network and the structural network formed by gap junctions, within the $\beta$-cells in the islets of Langerhans. Because the islet is a closed system with a relatively simple topology, we were able to form robust conclusions about the functional and structural network using both computational and experimental results. We conclude with five major points. First, the $\mathrm{Ca}^{2+}$-based functional network is not a good predictor of the gap-junction-based structural network. As such, it is highly inaccurate to conclude that a synchronized cell pair is connected via a gap junction or a chain of highly conductive gap junctions. Second, alterations in the structural network do influence functional network topology. Specifically, we show that decreasing gap junction conductance causes the functional network to become more sparse and less small world-like, which can have pathophysiologic implications. However, even in highly reduced coupling, the functional network is not random, indicating that there are intrinsic cell properties responsible for cellular synchronization. Third, alternative methods for quantifying small world-ness, such as local and global efficiency, should be used in highly sparse networks to reduce uncertainty. Fourth, we show that the property most correlated with $\mathrm{Ca}^{2+}$ synchronization in experiments and computational analyses is the $\beta$-cell metabolic activity, indicating that the functional network is more indicative of $\beta$-cell metabolism rather than gap junction structure. Fifth, medium-range synchronization (up to five cells apart) is correlated with chains of highly metabolically active cells. Chains of high gap junction conductance seem to be required for cells to synchronize over longer ranges (up to seven cells apart). These results provide novel insights into understanding the relationship between function and structure in islet networks and biological networks as a whole. 


\section{Methods:}

Calcium imaging, FRAP, and $N A D(P) H$

Animal care: Male and female mice were used under protocols approved by the University of Colorado Institutional Animal Care and Use Committee. $\beta$-cell-specific GCaMP6s expression ( $\beta$-GCaMP6s) was achieved through crossing a MIP-CreER (The Jackson Laboratory) and a GCaMP6s line (The Jackson Laboratory)(27). Genotype was verified through qPCR (Transetyx, Memphis, TN). Mice were held in a temperature-controlled environment with a $12 \mathrm{~h}$ light/dark cycle and given continuous access to food and water. CreER-mediated recombination was induced by 5 daily doses of tamoxifen $(50 \mathrm{mg} / \mathrm{kg}$ bw in corn oil) delivered IP.

Islet isolation and culture: Islets were isolated from mice under ketamine/xylazine anesthesia ( $80 \mathrm{and} 16 \mathrm{mg} / \mathrm{kg}$ ) by collagenase delivery into the pancreas via injection into the bile duct. The collagenase-inflated pancreas was surgically removed and digested. Islets were handpicked and planted into the glass-bottom dishes (MatTek) using CellTak cell tissue adhesive (Sigma-Aldrich). Islets were cultured in RPMI medium (Corning, Tewksbury, MA) containing $10 \%$ fetal bovine serum, $100 \mathrm{U} / \mathrm{mL}$ penicillin, and $100 \mathrm{mg} / \mathrm{mL}$ streptomycin. Islets were incubated at $37 \mathrm{C}, 5 \% \mathrm{CO} 2$ for $24-72 \mathrm{~h}$ before imaging.

Imaging: An hour prior to imaging nutrition media from the isolated islets was replaced by an imaging solution (125 mM NaCl, $5.7 \mathrm{mM} \mathrm{KCl}, 2.5 \mathrm{mM} \mathrm{CaCl}$, $1.2 \mathrm{mM} \mathrm{MgCl}$ 2, $10 \mathrm{mM} \mathrm{HEPES}$, and 0.1\% BSA, pH 7.4) containing 2 $\mathrm{mM}$ glucose. During imaging the glucose level was raised to $11 \mathrm{mM}$. Islets were imaged using either a LSM780 system (Carl Zeiss, Oberkochen, Germany) with a 40x 1.2 NA objective or with an LSM800 system (Carl Zeiss) with 20x 0.8 NA PlanApochromat objective, or a 40x 1.2 NA objective, with samples held at 37C.

For $\left[\mathrm{Ca}^{2+}\right]$ measurements GCaMP6s fluorescence was excited using a 488-nm laser. Images were acquired at 1 frame/s at 10-20 $\mu \mathrm{m}$ depth from the bottom of the islet. Glucose was elevated 3 minutes after the start of recording, unless stated otherwise.

$\mathrm{NAD}(\mathrm{P}) \mathrm{H}$ autofluorescence and $\left[\mathrm{Ca}^{2+}\right]$ dynamics were performed in the same z-position within the islet. $\mathrm{NADH}(\mathrm{P}) \mathrm{H}$ autofluorescence was imaged under two-photon excitation using a tunable mode-locked Ti:sapphire laser (Chameleon; Coherent, Santa Clara, CA) set to $710 \mathrm{~nm}$. Fluorescence emission was detected at 400-450 $\mathrm{nm}$ using the internal detector. Z-stacks of 6-7 images were acquired spanning a depth of $5 \mu \mathrm{m}$. First the $\mathrm{NAD}(\mathrm{P}) \mathrm{H}$ was recorded at $2 \mathrm{mM}$ glucose, then the $\left[\mathrm{Ca}^{2+}\right]$ dynamics was recorder at $2 \mathrm{mM}$ and during transition to $11 \mathrm{mM}$ glucose. After the $\left[\mathrm{Ca}^{2+}\right]$ wave was established, the $\mathrm{NAD}(\mathrm{P}) \mathrm{H}$ was recorded at $11 \mathrm{mM}$ glucose.

Cx36 gap junction permeability and $\left[\mathrm{Ca}^{2+}\right]$ dynamics were performed in the same z-position within the islet, with gap junction permeability measured using fluorescence recovery after photobleaching (FRAP), as previously described (39). After [ $\left.\mathrm{Ca}^{2+}\right]$ imaging, islets were loaded with $12 \mathrm{mM}$ Rhodamine- 123 for $30 \mathrm{~min}$ at $37 \mathrm{C}$ in imaging solution. Islets were then washed and FRAP performed at $11 \mathrm{mM}$ glucose at room temperature. Room temperature was used because at this temperature the Rhodamine-123 travels between the cells only through the $\mathrm{C} \times 36$ gap junctions, versus at $37 \mathrm{C}$ it can permeate a cell membrane. Rhodamine-123 was excited using a 488-nm laser line, and fluorescence emission was detected at 500-580 nm. Three baseline intensity images were initially recorded. A region of interest was then photobleached achieving, on average, a $50 \%$ decrease in fluorescence, and images were then acquired every 5-15 s for 15-30 min.

Analysis of $[\mathrm{Ca} 2+]$ dynamics: Pearson-product-based network analysis presented in Figure 2 was performed as previously reported (6). $\left[\mathrm{Ca}^{2+}\right]$ time courses were analyzed during the second-phase $\left[\mathrm{Ca}^{2+}\right]$ response, when the 
slow calcium wave was established. The Pearson product for each cell pair in the islet was calculated over each time point, and the time-average values were computed to construct a correlation matrix. An adjacency matrix was calculated by applying a threshold to the correlation matrix. The same threshold of 0.9 was applied to all islets. All cell pairs with a non-zero values in the adjacency matrix were considered to have a functional edge. The percent of edges was calculated with respect to the maximum number of edges per cell in each individual islet. For example, if a most connected cell possessed $\max =10$ edges, and other cells had $1,3, \ldots 7$ edges - then the $\%$ were: $10 \%, 30 \%, \ldots 70 \%$.

\section{Prior calcium imaging first presented in (13)}

Islet isolation: Islets were isolated as described in Scharp et al. (59) and Stefan et al. (60) and maintained in Roswell Park Memorial. Institute medium containing 10\% fetal bovine serum, $11 \mathrm{mM}$ glucose at 37C under humidified 5\% CO2 for 24-48 h before imaging.

Imaging islets: Isolated islets were stained with $4 \mathrm{mM}$ Fluo-4 AM (Invitrogen, Carlsbad, CA) in imaging medium (125 mM NaCl, $5.7 \mathrm{mM} \mathrm{KCl}, 2.5 \mathrm{CaCl} 2,1.2 \mathrm{mM} \mathrm{MgCl}$, $10 \mathrm{mM}$ HEPES, $2 \mathrm{mM}$ glucose, $0.1 \%$ bovine serum albumin, $\mathrm{pH}$ 7.4) at room temperature for $1-3 \mathrm{~h}$ before imaging. Islets were imaged in a polydimethylsiloxane (PDMS) microfluidic device, the fabrication of which has been previously described in Rocheleau et al. , which holds the islet stable for imaging and allows rapid reagent change, such as varying glucose stimulation or adding gap junction inhibitors. Fluo-4 fluorescence is imaged $15 \mathrm{~min}$ after a step increase in glucose from low (2 $\mathrm{mM}$ ) to high (11 mM). High speed imaging is performed on an LSM5Live with a 2030.8 NA Fluar Objective (Zeiss, Jena, Germany) using a $488 \mathrm{~nm}$ diode laser for excitation and a $495 \mathrm{~nm}$ long-pass filter to detect fluorescence emission. The microfluidic device is held on the microscope stage in a humidified temperature-controlled chamber, maintained at $37 \mathrm{C}$. Images were acquired at a rate of 4-6 frames per second, with average powers at the sample being minimized to, $200 \mathrm{~mW} / \mathrm{cm} 2$.

Analysis of Ca2+ Imaging data: We present data from 11 Islets from 6 WT mice, 11 Islets from 11 heterozygous Cx36 +/- knockout mice, and 14 Islets from 3 homozygous Cx36 -/- knockout mice. We extracted cell calcium dynamics by visually identifying and circling all cells in the islet. We assumed that the pixels within a cell should be well coordinated, so we removed any pixels whose dynamics were not within 5-10 STD of the average. This usually resulted in the removal of 1-5 pixels on the edge of the cell boundary.

Threshold: Previous studies have shown that wild type Islets should have a degree distribution that is roughly linear when plotted on a log-log plot and average degree between 5-15 $(6,30,34)$. To determine $R_{t h}$ that best satisfied both of these findings, we utilized constrained optimization matlab algorithm fminsearchbnd ( $D^{\prime}$ Errico, n.d.) to find the $R_{t h_{o p t}}$ which maximized the goodness of fit to a power law distribution, while forcing $5 \leq$ $k_{\text {avg }} \leq 15$ for each WT Islet constrained optimization. The average optimal threshold $\left(R_{t h}=0.90\right)$.

Average distance between connected cells: The average distance between connected cells calculated the total number of pixels between the center of two connected cells. The average distance was expressed as the normalized distance between connected cells and the average distance between all cells in the Islet to control for image and Islet size. 


\section{Computational Model:}

This ordinary differential equation model has been described previously (31) and validated on experimental studies $(40,52,63,64)$. It is based on a single $\beta$-cell electrophysiologic model (41), in which the membrane potential $\left(V_{i}\right)$ for $\beta$-cell $l_{i}$ is solved for each time step using eq 1a. We created a $1000 \beta$-cell network and electrically coupled any cell pairs within a small distance from each other. The coupling current, $I_{\text {coup }}$ is determined by the difference in voltage between the cell pair and the average coupling conductance $\left(g_{\text {coup }}\right.$ ) between them (1b). All code was written in $\mathrm{C}++$ and run on the SUMMIT supercomputer (University of Colorado Boulder). All simulations are run at $11 \mathrm{mMol}$ glucose. The membrane potential $\left(V_{i}\right)$ for $\beta$-cell $l_{i}$ is solved for using the ODE:

$$
\begin{gathered}
C_{m} \frac{d V_{i}}{d t}=I_{C a v}+I_{T R P M}+I_{S O C}+I_{b N S C}+I_{K D r}+I_{K C a(S K)}+I_{K_{A T P}}+I_{N a C a}+I_{P M C A}+I_{N a C a}+I_{C o u p} \\
I_{\text {Coup }}=\sum_{i} g_{\text {coup }}^{i j}\left(V_{i}-V_{j}\right)
\end{gathered}
$$

The average number of gap junction connections per cell was 5.24. Cellular heterogeneity was introduced by assigning randomized metabolic and electrical parameter values to each cell based on their distributions previously determined by experimental studies. For example, coupling conductance ( $g_{\text {coup }}$ ) was assigned so that the Islet average is $g_{\text {coup }}=0.12 n S$ and glucokinase $\left(k_{\text {glyc }}\right)$, the rate-limiting step in glycolysis, was assigned so that the average $k_{\text {glyc }}=1.26 * 10^{-04} \mathrm{sec}^{-1}$. We ran the simulation for 500 seconds and only the $2^{\text {nd }}$ phase was analyzed, in concordance with (30). All the results presented are based on five different Islets with randomized parameter values. $\beta$-cell heterogeneity was simulated by randomizing parameters including coupling conductance $\left(g_{\text {coup }}\right)$ and metabolic rate $\left(k_{\text {glyc }}\right)$ according to experimental results. To explore the effects of coupling conductance on the functional network, we altered Islet average coupling conductivity to $g_{\text {coup }}=$ $0.06 n S$ and $g_{\text {coup }}=0.03 n S$, and then assigning each cell a randomized $g_{\text {coup }}$ based on the new target average. The gap junction conductance $\left(g_{\text {coup }}\right.$ ) for any cell was calculated as the sum of the average conductivity $\left(g_{\text {coup }}\right)$ between the cell of interest and any cells it shares a gap junction connection with:

$$
g_{\text {coup }_{j}}=\sum_{i=1}^{m} \frac{1}{2}\left(g_{\text {coup }}^{i}+g_{\text {coup }}^{j}\right)
$$

\section{Network Analysis:}

Creating Functional Network from simulated Islet: The methodology was based on that previously defined in (6). First, the correlation coefficient between each cell was calculated using corr() function in matlab, which follows equation: $R_{i j}=\frac{\sum\left[\bar{x}_{i}-x_{i}(t)\right]\left[\bar{x}_{j}-x_{j}(t)\right]}{s_{x_{i}} s_{x_{j}}}$. Next, a threshold $\left(R_{t h}\right)$ was defined to determine whether each cell pair is 'synchronized' or 'not synchronized'. For computational experiments, the threshold was chosen such that the network followed a power law distribution, as predicted in $(6,30)$. Unless otherwise noted, $R_{t h}=0.9995$ for computational analysis. 
Creating the Metabolic network: Because gap junctions enforce localization onto the analysis, we looked at cell pairs whose Pythagorean distance was $\leq 15 \%$ of the Islet. Within this sample space, we looked at cell pairs whose average $k_{\text {glyc }}$ was higher than the Islet average (Figure $4 \mathbf{b}$, green) $\left(0.5 *\left|k_{g l y c_{i}}+k_{g l y c}\right|>\right.$ $\left.\operatorname{average}\left(0.5 *\left|k_{g l y c_{i}}+k_{g l y c}\right| \forall_{i_{j}}\right)\right)$, and cell pairs whose $\mathrm{K}_{\mathrm{glyc}}$ was more similar than the islet average $\left(\left|k_{g l y c}{ }_{i}-k_{g l y c_{j}}\right|<\operatorname{average}\left(\left|k_{g l y c_{i}}-k_{g l y c}\right| \forall_{i_{j}}\right)\right)$.

Average degree: The degree $k_{i}$ was calculated by counting the number of connections for cell $_{i}$ and averaging $\mathrm{k}$ over all cells in the Islet, then normalized to the Islet size to remove any size dependence $\left(\frac{k_{\text {avg }}}{n}\right.$, where $n \equiv$ islet size).

Degree Distribution: The degree distribution was calculated by first calculating the degree of each cell by taking the column sum of the adjacency matrix. Then each cell degree was normalized by dividing by the maximum degree in the Islet. The histogram was then calculated using GraphPad Prism.

Hub identification: In accordance with, any cell with more than $60 \%$ of the Islet's connections, calculated by the degree distribution, was considered a hub cell.

\section{Probabilities:}

We first created the functional network and structural (GJ related probabilities) or metabolic network (metabolism). We then calculated the probability that two cells were synchronized by:

$$
\operatorname{Pr}(\text { sync })=\frac{\frac{m_{\text {sync }}}{(n-1) * n}}{2}
$$

Where $m_{\text {sync }}=$ number of edges in the synchronized network, and $n=$ number of nodes. Similarly, we calculated the probability that two cells were either gap junction coupled or metabolically related using

$$
\operatorname{Pr}\left(G J \text { or } k_{g l y c}\right)=\frac{\frac{m_{G J \text { or } k_{g l y c}}}{(n-1) * n}}{2}
$$

Where $m_{G J \text { or } k_{\text {glyc }}}$ is the number of edges in the gap junction or metabolic network.

To find the probability that a cell pair was both synchronized and GJ or metabolically connected, we calculated

$$
\operatorname{Pr}(\text { both })=\frac{\frac{m_{\text {both }}}{(n-1) * n}}{2}
$$

Where $m_{\text {both }}$ is any edge that exists in both matrices.

Finally, we calculated conditional probabilities by:

$$
\operatorname{Pr}(\text { sync } \mid G J)=\frac{\operatorname{Pr}(\text { both })}{\operatorname{Pr}(G J)}
$$




$$
\operatorname{Pr}(G J \mid \text { sync })=\frac{\operatorname{Pr}(\text { both })}{\operatorname{Pr}(\text { sync })}
$$

These quantities were calculated separately for each Islet seed and then averaged.

\section{Network topology analysis:}

Clustering Coefficient: The clustering coefficient represents the 'cliquishness' of the network . This is defined by (6) as the "number of existing connections between all neighbors of a node, divided by the number of all possible connections between them." This was calculated by making a subgraph of each cell's connections and counting the number of connections between those cells. For example, if $A$ is connected to $B, C$, and $D$, and $B$ and $C$ are connected but $D$ is not connected to any other cell (see matrix). Then the clustering for cell $A$ is $\frac{2}{3 * 2}=\frac{1}{3}$. Each node is a assigned a clustering coefficient $C$ such that:

\begin{tabular}{|l|l|l|l|}
\hline $\begin{array}{l}\text { Subgraph } \\
\text { - A }\end{array}$ & B & C & D \\
\hline B & & 1 & 0 \\
\hline C & 1 & & 0 \\
\hline D & 0 & 0 & \\
\hline
\end{tabular}

The average clustering coefficient is $C_{\text {avg }}=\frac{1}{n} \sum_{i}^{n} C_{i}$.

Average Shortest Path Length: Shortest path length was calculated with matlab function graphallshortestpaths(). This function uses the Johnson's algorithm (65) to find the shortest path between every pair of cell in the Islet. For example, the path length between cell $_{i}$ and $c e l l_{j}$ is 1 if they are directly synchronized, or 2 if $c e l l_{i}$ is not synchronized with cell $_{j}$ but each is synchronized with cell $_{k}$. To compensate for highly sparse network, any non-connected node was given a characteristic path length of $n+1$. Finally, the characteristic path length (L), or average path length, was expressed as the sum of all path lengths normalized to total possible connections (size*(size-1)).

The normalized average shortest path length (Supplemental $2 \mathrm{~d}$ ) is therefore calculated as $L_{\text {avg }}=$ $\frac{1}{n} \frac{1}{n} \sum_{i=1}^{n} \sum_{j=1}^{n} L_{i j}$. To compensate for any non-connected cell, whose path length $L_{i x}=\infty$, where $x$ is any cell in the Islet, we set the path length for non-connected cells to $L_{i x} \rightarrow n+1$ where $n$ is the number of cells in the Islet.

Global Efficiency: The global efficiency is related to the inverse of global path length (44).

$$
\boldsymbol{E}_{\{\text {global }\}}=\frac{1}{\text { Islet }_{\text {size }} *\left(\text { Islet }_{\text {size }}-1\right)} \sum_{j k} \frac{1}{L_{j k}}
$$

length using $E_{\text {global }}=\frac{1}{n(n-1)} \sum_{i=1}^{n} \sum_{j=1}^{n} \frac{1}{L_{i j}}$. Because $E_{\text {global }}=0$ for a non-connected cell, the disconnected network is naturally compensated for. 
Random Networks: Random networks were created using an Erodos Renyi approach (66). For each Islet, we created 1000 random networks with equal number of nodes, edges, and average degree as the Islet of interest. The probability that two cells were connected was given by $P=\frac{k_{\text {avg }}}{n}$. For each cell pair within the Islet, a random number generator created a number from $0-1$. If that number was below $P$, those cells were connected by an edge.

Small World properties: For each Islet, small world parameters $S_{E}$ and $S_{L}$ were calculated 1000 times based on the 1000 random networks.

$$
\begin{array}{r}
S_{L}=\frac{\frac{C_{\text {avg }}}{C_{\text {rand }}}}{\frac{L_{\text {avg }}}{L_{\text {rand }}}} \\
S_{E}=\frac{\frac{C_{\text {avg }}}{C_{\text {rand }}}}{\frac{E_{\text {rand }}}{E_{\text {avg }}}}
\end{array}
$$

Local Efficiency: Local efficiency is calculated by first extracting a subgraph based on the connections for an individual cell. Within that cell, the efficiency is calculated by:

$$
E=\frac{1}{n_{i} *\left(n_{i}-1\right)} \sum \frac{1}{L_{j, k}}
$$

Where $n_{i}$ is the number of nodes that an individual node is connected to. This is done for every node in the network and all efficiencies are averaged to present the local efficiency of the network.

Shortest weighted path length: The gap junction network was weighted using the inverse of $\mathrm{g}_{\text {coup }}$ or $\mathrm{k}_{\mathrm{glyc}}$ between $\operatorname{Cell}_{i}$ and $\operatorname{Cell}_{i}: W_{i j}=\frac{1}{\frac{1}{2}\left(g_{\text {coup }_{i}}+g_{\text {coup }}\right)}$ or $W_{i j}=\frac{1}{\frac{1}{2}\left(k_{\text {glyc }}+k_{\text {glyc }}\right)}$. This is done because the shortest path length algorithm views weights as "resistance" and finds the path of least resistance. The shortest weighted path between every cell was calculated using Johnson's algorithm (65). Cell pairs were then categorized as synchronized or not synchronized if their correlation coefficient was $<R_{t h}$. The average for synchronized and non-synchronized cells was calculated over each Islet for each distance. To normalize over distance, each data point was divided by the average of the non-synchronized and synchronized islets for the given distance.

\section{Significance Testing:}

Significance tests are done in Prism (GraphPad).

The computational model is run on 5 seeds, therefore all significance tests are paired.

Figure $1 \mathrm{e}-\mathrm{g}$, Figure $4 \mathrm{e} \& \mathrm{~h}$, and Figure $5 \mathrm{c}-\mathrm{f}$ are paired, two tailed t-tests.

Figure $3 e, f$ are repeated measures paired one-way ANOVA with multiple comparison using uncorrected Fsher's least squared difference.

All significance tests in figure 6 are unpaired ordinary one-way ANOVA tests. 
bioRxiv preprint doi: https://doi.org/10.1101/2022.02.06.479331; this version posted February 9, 2022. The copyright holder for this preprint (which was not certified by peer review) is the author/funder. All rights reserved. No reuse allowed without permission.

Figure 7 c-j are ordinary paired one-way ANOVA with Tukey multiple comparison test.

Supplemental $1 \mathrm{~b}$ and $2 \mathrm{~b}$, Figure $4 \mathrm{i}$ and $\mathrm{j}$ and Figure $5 \mathrm{i}$ : To compare, we used a paired T-test with Bonferroni multiple comparisons corrections. Since we there were 15 cell distances, we set the significance threshold $\alpha=$ 0.003. For convenience, we present asterisks next to significant $P$-values. 


\section{References}

1. M. Koutrouli, E. Karatzas, D. Paez-Espino, G. A. Pavlopoulos, A guide to conquer the biological network era using graph theory. Frontiers in bioengineering and biotechnology 8, 34 (2020).

2. Z. Dai, C. Yan, K. Li, Z. Wang, J. Wang, M. Cao, Q. Lin, N. Shu, M. Xia, Y. Bi, others, Identifying and mapping connectivity patterns of brain network hubs in Alzheimer's disease. Cerebral cortex 25, 3723-3742 (2015).

3. T. Proix, F. Bartolomei, M. Guye, V. K. Jirsa, Individual brain structure and modelling predict seizure propagation. Brain 140, 641-654 (2017).

4. E. Bullmore, O. Sporns, Complex brain networks: graph theoretical analysis of structural and functional systems. Nature reviews neuroscience 10, 186-198 (2009).

5. C. W. Lynn, D. S. Bassett, The physics of brain network structure, function and control. Nature Reviews Physics 1, 318-332 (2019).

6. A. Stožer, M. Gosak, J. Dolenšek, M. Perc, M. Marhl, M. S. Rupnik, D. Korošak, Functional connectivity in islets of Langerhans from mouse pancreas tissue slices. PLoS Comput Biol 9, e1002923 (2013).

7. D. J. Hodson, M. Schaeffer, N. Romanò, P. Fontanaud, C. Lafont, J. Birkenstock, F. Molino, H. Christian, J. Lockey, D. Carmignac, others, Existence of long-lasting experience-dependent plasticity in endocrine cell networks. Nature communications 3, 1-10 (2012).

8. C. Grienberger, A. Konnerth, Imaging calcium in neurons. Neuron 73, 862-885 (2012).

9. F. A. Azevedo, L. R. Carvalho, L. T. Grinberg, J. M. Farfel, R. E. Ferretti, R. E. Leite, W. J. Filho, R. Lent, S. Herculano-Houzel, Equal numbers of neuronal and nonneuronal cells make the human brain an isometrically scaled-up primate brain. Journal of Comparative Neurology 513, 532-541 (2009).

10. J. R. Burger, M. A. George Jr, C. Leadbetter, F. Shaikh, The allometry of brain size in mammals. Journal of Mammalogy 100, 276-283 (2019).

11. L. W. de Jong, J.-S. Vidal, L. E. Forsberg, A. P. Zijdenbos, T. Haight, A. D. N. Initiative, S. Sigurdsson, V. Gudnason, M. A. van Buchem, L. J. Launer, Allometric scaling of brain regions to intra-cranial volume: An epidemiological MRI study. Human brain mapping 38, 151-164 (2017).

12. R. K. Benninger, V. Kravets, The physiological role of $\beta$-cell heterogeneity in pancreatic islet function. Nature Reviews Endocrinology 18, 9-22 (2022).

13. R. K. Benninger, M. Zhang, W. S. Head, L. S. Satin, D. W. Piston, Gap junction coupling and calcium waves in the pancreatic islet. Biophysical journal 95, 5048-5061 (2008).

14. J. Weitz, D. Menegaz, A. Caicedo, Deciphering the Complex Communication Networks That Orchestrate Pancreatic Islet Function. Diabetes 70, 17-26 (2021).

15. A. Kim, K. Miller, J. Jo, G. Kilimnik, P. Wojcik, M. Hara, Islet architecture: A comparative study. Islets 1, 129136 (2009).

16. D. J. Steiner, A. Kim, K. Miller, M. Hara, Pancreatic islet plasticity: interspecies comparison of islet architecture and composition. Islets 2, 135-145 (2010). 
17. V. Serre-Beinier, S. Le Gurun, N. Belluardo, A. Trovato-Salinaro, A. Charollais, J.-A. Haefliger, D. F. Condorelli, P. Meda, Cx36 preferentially connects beta-cells within pancreatic islets. Diabetes 49, 727-734 (2000).

18. M. A. Ravier, M. Güldenagel, A. Charollais, A. Gjinovci, D. Caille, G. Söhl, C. B. Wollheim, K. Willecke, J.-C. Henquin, P. Meda, Loss of connexin36 channels alters $\beta$-cell coupling, islet synchronization of glucose-induced Ca2+ and insulin oscillations, and basal insulin release. Diabetes 54, 1798-1807 (2005).

19. W. S. Head, M. L. Orseth, C. S. Nunemaker, L. S. Satin, D. W. Piston, R. K. Benninger, Connexin-36 gap junctions regulate in vivo first-and second-phase insulin secretion dynamics and glucose tolerance in the conscious mouse. Diabetes 61, 1700-1707 (2012).

20. L. S. Satin, P. C. Butler, J. Ha, A. S. Sherman, Pulsatile insulin secretion, impaired glucose tolerance and type 2 diabetes. Mol Aspects Med 42, 61-77 (2015).

21. P. Bratusch-Marrain, M. Komjati, W. Waldhäusl, Efficacy of pulsatile versus continuous insulin administration on hepatic glucose production and glucose utilization in type I diabetic humans. Diabetes $\mathbf{3 5}$, 922-926 (1986).

22. N. Pørksen, M. Hollingdal, C. Juhl, P. Butler, J. D. Veldhuis, O. Schmitz, Pulsatile insulin secretion: detection, regulation, and role in diabetes. Diabetes 51, S245-S254 (2002).

23. A. V. Matveyenko, D. Liuwantara, T. Gurlo, D. Kirakossian, C. Dalla Man, C. Cobelli, M. F. White, K. D. Copps, E. Volpi, S. Fujita, others, Pulsatile portal vein insulin delivery enhances hepatic insulin action and signaling. Diabetes 61, 2269-2279 (2012).

24. D. J. Hodson, R. K. Mitchell, E. A. Bellomo, G. Sun, L. Vinet, P. Meda, D. Li, W.-H. Li, M. Bugliani, P. Marchetti, others, Lipotoxicity disrupts incretin-regulated human $\beta$ cell connectivity. The Journal of clinical investigation 123, 4182-4194 (2013).

25. D. A. Lang, D. Matthews, M. Burnett, R. Turner, Brief, irregular oscillations of basal plasma insulin and glucose concentrations in diabetic man. Diabetes 30, 435-439 (1981).

26. J. R. St Clair, M. J. Westacott, N. L. Farnsworth, V. Kravets, W. E. Schleicher, J. G. Miranda, A. Heintz, N. W. Ludin, R. K. Benninger, Restoring connexin-36 function in diabetogenic environments precludes mouse and human islet dysfunction. bioRxiv (2020).

27. M. E. C. do Amaral, V. Kravets, J. M. Dwulet, N. L. Farnsworth, R. Piscopio, W. E. Schleicher, J. G. Miranda, R. K. Benninger, Caloric Restriction recovers impaired $\beta$-cell- $\beta$-cell coupling, calcium oscillation coordination and insulin secretion in prediabetic mice. bioRxiv (2020).

28. M. Gosak, R. Markovič, J. Dolenšek, M. S. Rupnik, M. Marhl, A. Stožer, M. Perc, Network science of biological systems at different scales: A review. Physics of life reviews 24, 118-135 (2018).

29. R. Markovič, A. Stožer, M. Gosak, J. Dolenšek, M. Marhl, M. S. Rupnik, Progressive glucose stimulation of islet beta cells reveals a transition from segregated to integrated modular functional connectivity patterns. Sci Rep 5, 7845 (2015).

30. N. R. Johnston, R. K. Mitchell, E. Haythorne, M. P. Pessoa, F. Semplici, J. Ferrer, L. Piemonti, P. Marchetti, M. Bugliani, D. Bosco, others, Beta cell hubs dictate pancreatic islet responses to glucose. Cell metabolism 24, 389-401 (2016). 
31. J. M. Dwulet, J. K. Briggs, R. K. P. Benninger, Small subpopulations of beta-cells do not drive islet oscillatory [Ca2+] dynamics via gap junction communication. PLOS Computational Biology 17, e1008948 (2021).

32. C.-L. Lei, J. A. Kellard, M. Hara, J. D. Johnson, B. Rodriguez, L. J. Briant, Beta-cell hubs maintain Ca2+ oscillations in human and mouse islet simulations. Islets 10, 151-167 (2018).

33. V. Salem, L. D. Silva, K. Suba, E. Georgiadou, S. N. M. Gharavy, N. Akhtar, A. Martin-Alonso, D. C. Gaboriau, S. M. Rothery, T. Stylianides, others, Leader beta-cells coordinate $\mathrm{Ca} 2+$ dynamics across pancreatic islets in vivo. Nature Metabolism 1, 615-629 (2019).

34. D. Korošak, M. Jusup, B. Podobnik, A. Stožer, J. Dolenšek, P. Holme, M. S. Rupnik, Autopoietic influence hierarchies in pancreatic \$ \beta\$-cells. arXiv:2101.02255 [cond-mat, physics:physics] (2021) (available at http://arxiv.org/abs/2101.02255).

35. L. S. Satin, Q. Zhang, P. Rorsman, "Take Me To Your Leader": An Electrophysiological Appraisal of the Role of Hub Cells in Pancreatic Islets. Diabetes 69, 830-836 (2020).

36. G. A. Rutter, N. Ninov, V. Salem, D. J. Hodson, Comment on Satin et al."Take me to your leader": an electrophysiological appraisal of the role of hub cells in pancreatic islets. Diabetes 2020; 69: 830-836. Diabetes 69, e10-e11 (2020).

37. L. S. Satin, P. Rorsman, Response to comment on satin et al. "Take me to your leader": An electrophysiological appraisal of the role of hub cells in pancreatic islets. Diabetes 2020; 69: 830-836. Diabetes 69, e12-e13 (2020).

38. Q. Zhang, J. Galvanovskis, F. Abdulkader, C. J. Partridge, S. O. Göpel, L. Eliasson, P. Rorsman, Cell coupling in mouse pancreatic $\beta$-cells measured in intact islets of Langerhans. Philosophical Transactions of the Royal Society A: Mathematical, Physical and Engineering Sciences 366, 3503-3523 (2008).

39. N. L. Farnsworth, A. Hemmati, M. Pozzoli, R. K. Benninger, Fluorescence recovery after photobleaching reveals regulation and distribution of connexin36 gap junction coupling within mouse islets of Langerhans. The Journal of physiology 592, 4431-4446 (2014).

40. T. H. Hraha, M. J. Westacott, M. Pozzoli, A. M. Notary, P. M. McClatchey, R. K. Benninger, Phase transitions in the multi-cellular regulatory behavior of pancreatic islet excitability. PLoS computational biology 10, e1003819 (2014).

41. C. Y. Cha, Y. Nakamura, Y. Himeno, J. Wang, S. Fujimoto, N. Inagaki, Y. E. Earm, A. Noma, Ionic mechanisms and $\mathrm{Ca} 2+$ dynamics underlying the glucose response of pancreatic beta cells: a simulation study. Journal of General Physiology 138, 21-37 (2011).

42. M. Newman, Networks (Oxford university press, 2018).

43. D. J. Watts, S. H. Strogatz, Collective dynamics of 'small-world'networks. nature 393, 440-442 (1998).

44. V. Latora, M. Marchiori, Efficient behavior of small-world networks. Physical review letters 87, 198701 (2001).

45. M. T. Adams, J. M. Dwulet, J. K. Briggs, C. A. Reissaus, E. Jin, J. M. Szulczewski, M. R. Lyman, S. M. Sdao, V. Kravets, S. D. Nimkulrat, others, Reduced synchroneity of intra-islet Ca2+ oscillations in vivo in Robo-deficient $\beta$ cells. Elife 10 (2021). 
46. N. L. Farnsworth, R. K. Benninger, New insights into the role of connexins in pancreatic islet function and diabetes. FEBS letters 588, 1278-1287 (2014).

47. A. Sherman, J. Rinzel, Model for synchronization of pancreatic beta-cells by gap junction coupling. Biophysical journal 59, 547-559 (1991).

48. S. Boccaletti, V. Latora, Y. Moreno, M. Chavez, D.-U. Hwang, Complex networks: Structure and dynamics. Physics reports 424, 175-308 (2006).

49. S. Milgram, The small world problem. Psychology today 2, 60-67 (1967).

50. N. L. Farnsworth, R. L. Walter, A. Hemmati, M. J. Westacott, R. K. Benninger, Low level pro-inflammatory cytokines decrease connexin36 gap junction coupling in mouse and human islets through nitric oxide-mediated protein kinase C $\delta$. Journal of Biological Chemistry 291, 3184-3196 (2016).

51. R. K. Benninger, D. J. Hodson, New understanding of $\beta$-cell heterogeneity and in situ islet function. Diabetes 67, 537-547 (2018).

52. M. J. Westacott, N. W. Ludin, R. K. Benninger, Spatially organized $\beta$-cell subpopulations control electrical dynamics across islets of Langerhans. Biophysical journal 113, 1093-1108 (2017).

53. R. Bertram, A. Sherman, L. S. Satin, Electrical bursting, calcium oscillations, and synchronization of pancreatic islets. The Islets of Langerhans , 261-279 (2010).

54. J.-C. Henquin, Paracrine and autocrine control of insulin secretion in human islets: evidence and pending questions. American Journal of Physiology-Endocrinology and Metabolism 320, E78-E86 (2021).

55. T. Moede, I. B. Leibiger, P.-O. Berggren, Alpha cell regulation of beta cell function. Diabetologia 63, 20642075 (2020).

56. T. Van Der Meulen, C. J. Donaldson, E. Cáceres, A. E. Hunter, C. Cowing-Zitron, L. D. Pound, M. W. Adams, A. Zembrzycki, K. L. Grove, M. O. Huising, Urocortin3 mediates somatostatin-dependent negative feedback control of insulin secretion. Nature medicine 21, 769-776 (2015).

57. R. A. e Drigo, S. Jacob, C. F. García-Prieto, X. Zheng, M. Fukuda, H. T. T. Nhu, O. Stelmashenko, F. L. M. Peçanha, R. Rodriguez-Diaz, E. Bushong, others, Structural basis for delta cell paracrine regulation in pancreatic islets. Nature communications 10, 1-12 (2019).

58. C. Miranda, M. Begum, E. Vergari, L. J. Briant, Gap junction coupling and islet delta-cell function in health and disease. Peptides 147, 170704 (2022).

59. D. W. SCHARP, C. B. KEMP, M. J. KNIGHT, W. F. BALLINGER, P. E. LACY, The use of ficoll in the preparation of viable islets of langerhans from the rat pancreas. Transplantation 16, 686-688 (1973).

60. Y. Stefan, P. Meda, M. Neufeld, L. Orci, others, Stimulation of insulin secretion reveals heterogeneity of pancreatic B cells in vivo. The Journal of clinical investigation 80, 175-183 (1987).

61. J. V. Rocheleau, M. S. Remedi, B. Granada, W. S. Head, J. C. Koster, C. G. Nichols, D. W. Piston, Critical role of gap junction coupled KATP channel activity for regulated insulin secretion. PLoS biology 4, e26 (2006). 
62. J. D'Errico, fminsearchbnd, fminsearchcon

(https://www.mathworks.com/matlabcentral/fileexchange/8277-fminsearchbnd-fminsearchcon). MATLAB Central File Exchange.

63. A. M. Notary, M. J. Westacott, T. H. Hraha, M. Pozzoli, R. K. P. Benninger, Decreases in Gap Junction Coupling Recovers Ca2+ and Insulin Secretion in Neonatal Diabetes Mellitus, Dependent on Beta Cell Heterogeneity and Noise. PLOS Computational Biology 12, e1005116 (2016).

64. J. M. Dwulet, N. W. Ludin, R. A. Piscopio, W. E. Schleicher, O. Moua, M. J. Westacott, R. K. Benninger, How heterogeneity in glucokinase and gap-junction coupling determines the islet [Ca2+] response. Biophysical journal 117, 2188-2203 (2019).

65. D. B. Johnson, Efficient algorithms for shortest paths in sparse networks. Journal of the ACM (JACM) 24, 113 (1977).

66. P. Erd\Hos, A. Rényi, On the evolution of random graphs. Publ. Math. Inst. Hung. Acad. Sci 5, 17-60 (1960). 


\section{Acknowledgements}

Richard KP Benninger (University of Colorado) is the guarantor of this work and, as such, had full access to all the data in the study and takes responsibility for the integrity of the data and the accuracy of the data analysis. We thank David W Piston (Washington University St Louis) with whom data presented in figure 6 was previously acquired. We thank Aaron Clauset and David Albers for helpful conversations and advice. All authors acknowledge that no conflict of interest exists. This work was supported by National Institute of Health (NIH) grants R01 DK102950, R01 DK106412 (to RKPB); by National Science Foundation (NSF) grant DGE1938058_Briggs. (to JKB); by JDRF grant 3-PDF-2019-741-A-N, Beckman Research Institute-City of Hope (HIRN) grant 25B1104 (to VK); by NIH grant F31 DK126360 (to JMD). The authors are grateful for utilization of the SUMMIT supercomputer from the University of Colorado Boulder Research Computing Group, which is supported by the National Science Foundation (awards ACl-1532235 and ACl-1532236), the University of Colorado Boulder, and Colorado State University. Microscopy use was supported in part by NIH grant P30 DK116073 and the University of Colorado Neurotechnology center. The funders had no role in the study design, data collection, and analysis, decisions to publish, or preparation of the manuscript. 
bioRxiv preprint doi: https://doi.org/10.1101/2022.02.06.479331; this version posted February 9, 2022. The copyright holder for this preprint (which was not certified by peer review) is the author/funder. All rights reserved. No reuse allowed without permission.

\section{Table Captions}

\section{Table 1: Essential network statistics and types}

Left: Five networks statistics used to quantify the network in this paper. Representative networks show an example of the statistic in red and the rest of the network in blue.

Right: Five network types referred to in this paper. Regular, small world, and random networks are all made with the same number of nodes and edges, but different configurations of edges. Scale free network shows three "hub" nodes where node size is proportional to degree. 


\section{Figure Captions}

Figure 1: Analysis of parameters underlying highly connected cells in a simulated islet network.

a: schematic of $1000 \beta$-cell computational model, with cells false-colored by heterogeneity in $\mathrm{k}_{\mathrm{glyc}}$ (left) and $\mathrm{g}_{\text {coup }}$ (right) parameter values. b: Distribution of functional connections (edges), determined from functional network analysis. Colors show five seeds. Hub cells (red outline) are any cell with $>60 \%$ of maximum number of links. The $R^{2}$ for linear fit was 0.559. c: 2-dimensional slice of the simulated islet, with lines (edges) representing functional connections between synchronized cells. Hub cells indicated in red. Slice is taken from middle of the Islet (see inset). d: Representative [ $\left.\mathrm{Ca}^{2+}\right]$ time-course of a hub (red) and non-hub (blue). Inset shows zoomed enlarged signal from $45-80$ seconds. e: Average rate of metabolism $\left(k_{\text {glyc }}\right)$ parameter values compared between hub and non-hub, retrospectively analyzed. $\mathbf{f}$ : as in e for maximum conductance of ATP sensitive potassium channel ( $\left.\mathrm{g}_{\text {КАTP }}\right)$. g: as in e for gap junction conductance $\left(g_{\text {coup }}\right)$. Significance in e-g was determined by paired Students t-test. ${ }^{*} P \leq 0.05$ and ${ }^{* *} P \leq 0.001$

\section{Figure 2: Comparison of the calcium-based network with the metabolic activity, NAD(P)H and coupling}

\section{conductance}

a: Mouse pancreatic islet expressing fluorescent calcium indicator GCaMP6s in $\beta$-cells. Glucose level $11 \mathrm{mM}$. b: GCamp6s time traces recorded at 2- and 11-mM glucose. Red curves represent dynamics of the most coordinated cells. These cells had highest number of edges, i.e., normalized degree $>0.9$. Green curves represent dynamics of the least coordinated cells, i.e., normalized degree $<0.1$, the rest of the cells are shown in grey. c: $\mathrm{Ca}^{2+}$ - based functional network of the islet shown in (e). Red dots represent most coordinated cells, and green dots - least coordinated cells which had at least 1 edge. d: Degree distribution of all eight analyzed islets. Threshold of $\mathrm{R}_{\mathrm{th}}=0.9$ was used to filter the Pearson-based coordination matrix and obtain the functional network. e: Left: Mouse pancreatic islet expressing fluorescent calcium indicator GCaMP6s. Glucose level $11 \mathrm{mM}$. Middle: $\mathrm{NAD}(\mathrm{P}) \mathrm{H}$ autofluorescence of the same islet and the same cell layer, recorded at $2 \mathrm{mM}$ glucose. Right: : NAD(P)H autofluorescence recorded at $11 \mathrm{mM}$ glucose. $\mathrm{f}$ : Change of the NAD(P)H levels in each cell in response to glucose elevation, with respect to the islet-average change. Metabolic activity here is compared for connected and disconnected cells. g: Change in $\mathrm{NAD}(\mathrm{P}) \mathrm{H}$ levels in response to glucose elevation, with respect to the isletaverage change: here comparison is made for the most coordinated cells (normalized degree $>0.9$ ) with the less coordinated cells (normalized degree $>0.8,>0.7,>0.6, \ldots<0.2,<0.1$ ). $\mathrm{f}, \mathrm{g}$ represent $\mathrm{n}=5$ islets with a total of 131 cells. $\mathbf{h}$ : Rhodamine123 fluorescence of the same islet and the same cell layer as in $\boldsymbol{a}$, recorded immediately after photobleaching of the bottom half of the islet (left) and recorded at 360 seconds after the photobleaching (right). i: Time trace of the fluorescence recovery after photobleaching (FRAP) of the lower half of the islet, shown in $\mathbf{h}$. The rate of recovery is proportional to the Cx36 gap junction permeability of each cell. j: FRAP recovery rate $\left(\mathrm{sec}^{-1}\right)$ in each of the photobleached cells: here the comparison is made for the most coordinated cells (normalized degree $>90 \%$ ) with the less coordinated cells (normalized degree $>80,>70,>60, \ldots<20,<10 \%$ ). j shows results from 4 islets and 202 cells). All the cells in this graph had a degree larger than 0.01 .

\section{Figure 3: Comparison of functional connections, gap junction junctions, and glucose metabolism}

a: Functional connections and structural connections for a representative highly connected $\beta$-cell hub, average cell, and low connected cell. Blue cells and edges indicate cells determined as "synchronized" via functional network analysis. Red cells are GJ coupled. Black cells are both GJ coupled and synchronized. b: Probability that a cell is synchronized given it is gap junction coupled, or vice versa, that a cell is gap junction coupled given it is synchronized. c: Ven diagram showing overlap between the synchronized cells and gap junction coupled cells 
within the simulated islet. $\mathbf{d}$ : Functional connections and metabolic connections for a beta cell hub and a cell with averaged synchronization. Blue cells and edges indicate cells determined as "synchronized" via functional network analysis. Green cells and edges indicate cells that have similar $k_{\text {glyc }}$ and are within $15 \%$ of the islet from each other. Black cells and edges indicate both synchronized and similar kglyc. e: Probability that a cell pair is synchronized given it shares a gap junction, has high average $k_{\text {glyc }}$ or has similar $k_{\text {glyc. }} \mathbf{f}$ : Probability that the cell pair is gap junction coupled, has higher than average $k_{\mathrm{glyc}}$ and within $15 \%$ of islet distance $(\operatorname{Pr}=0.024)$, or has similar $k_{\text {glyc }}$ and within $15 \%$ of islet distance $(\operatorname{Pr}=0.024)$, respectively, given the pair is synchronized. g: Ven diagram showing overlap between the synchronized cells and metabolically similar cells. Shaded area in c and $g$ is proportional to indicated probability. Significance in e and $f$ was determined by an uncorrected Fisher's LSD $* * P \leq 0.01$.

Figure 4: Comparison of long-range functional synchronization, gap junction network, and glucose metabolism.

a: Functional connections and gap junction connections for a representative cell (black). Synchronized cells in blue, gap junction coupled cells in red. Inset shows representative structural network (grey). b: Two representative cells (black) and the shortest path to a synchronized cell (blue) and a non-synchronized cell

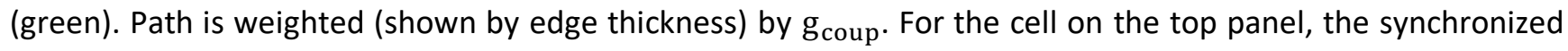
path has a higher cumulative gap junction conductivity $(0.68 \mathrm{nS})$ than the non synchronized path (0.43 nS). for the cell on the bottom panel, the synchronized path has a lower cumulative gap junction conductance $(0.74 \mathrm{nS})$ than the non synchronized path $(1.02 \mathrm{nS})$. c: Probability distribution of total $\mathrm{g}_{\text {coup }}$ for synchronized cells (blue) and non-synchronized cells (green) that are directly connected by gap junctions. d: As in c for cells pairs that are 7 cells apart. e: Comparison of the total $g_{\text {coup }}$, normalized by distance for synchronized cells (blue) and nonsynchronized cells (green). Each dot indicates the average resistance for a single simulated islet. f: As in c but with connections weighted by rate of metabolism. $g$ : As in $\mathrm{d}$ but with connections weighted by the rate of glucose metabolism. $\mathbf{h}$ : As in e but with connections weighted by the rate of glucose metabolism. i: Total gcoup for synchronized and non synchronized cells organized by cell distance. j: As in i but for metabolically weighted network. Significance in e, $\mathrm{h}$ was assessed by a two-tailed paired t-test, with $\mathrm{P}$ value indicated. Significance in $\mathrm{i}$ and $\mathrm{j}$ was, assessed by paired t-tests with Bonferroni correction. Reported $\mathrm{P}$ values are adjusted. ${ }^{*} P \leq 0.05$, ${ }^{* *} P \leq 0.01,{ }^{* * *} P \leq 0.001$.

Figure 5: Assessment of functional and structural network overlap in a correlated distribution of glucose metabolism and gap junction conductance

a: Distribution where $\mathrm{g}_{\text {coup }}$ is correlated with $\mathrm{k}_{\mathrm{glyc}}$, such that cells with high metabolism also have high gap junction coupling. b: 2-dimensional slice of the simulated islet, with lines (edges) representing functional connections between synchronized cells. Beta cell hub are indicated in red. Slice is taken from middle of the Islet (see inset). c: Average degree comparing proportional distribution shown in a and normal distribution (Figure $1)$, where there is no relationship between $k_{\text {glyc }}$ and $\mathbf{g}_{\text {coup }} \mathbf{d}$ : Average rate of glucose metabolism $\left(k_{\text {glyc }}\right)$ parameter values compared between hub and non-hub, retrospectively analyzed. e: as in $d$ for gap junction conductance $\left(g_{\text {coup }}\right)$. $f$ : as in $d$ for maximum conductance of ATP sensitive potassium channel $\left(g_{\text {KATP }}\right)$. $g$ : probability of synchronization given a cell pair is gap junction coupled $P(S y n c \mid G J)$, and probability that a cell pair which is gap junction coupled, is synchronized $P(G J \mid S y n c)$. h: Venn diagram showing overlap between synchronized cell pairs and gap junction connected cell pairs. i: Total $g_{\text {coup }}$ for synchronized and not synchronized cell pairs organized by cell distance. Shaded area in $\mathrm{h}$ is proportional to indicated probability. Significance in c-g 
was determined by 2-tailed paired Students t-test. Significance in i was assessed by paired t-tests with Bonferroni correction. ${ }^{*} P \leq 0.05,{ }^{* *} P \leq 0.01,{ }^{* * *} P \leq 0.001$.

\section{Figure 6: Experimental islet functional network is influenced by changes in the structural network}

a: Representative images of $\mathrm{C} \times 36^{+/+}$islet (left), heterozygous $\mathrm{C} \times 36^{+/-}$islet (middle), and homozygous $\mathrm{Cx} 36^{-/-}$islet (right), overlaid with a synchronization network. Dot signifies a cell, blue lines represent functional network edges that connect synchronized cells. Red cells are beta cell hubs. b: Oscillations in $\left[\mathrm{Ca}^{2+}\right]$ of corresponding islet in a. grey lines represent time-course for each cell, colored line represents mean islet time-course. c: Frequency histograms of connections for the corresponding Islet in a. Connections are calculated using functional network analysis and normalized to the maximum degree in the Islet. As such $100 \%$ links represents the cell with the greatest total number of connections. d: Normalized degree of functional network between cell pairs, averaged over islets of each $\mathrm{C} \times 36^{+/+}, \mathrm{C} \times 36^{+/-}, \mathrm{C} \times 36^{-/-}$mouse. e: Percent of cells in the Islet which have are not connected to any other cell (eg. All $R_{i j}<R_{t h}$ ). f: Average clustering coefficient. Overlaid is the box and whisker plot of 1000 random networks per Islet created with the same number of nodes, edges, and degree as the islet. g: Average Shortest path length. Overlaid is the box and whisker plot of 1000 random networks per islet, as in $\mathrm{f}$. $\mathbf{h}$ : Average Global Efficiency. Overlaid is the box and whisker plot of 1000 random networks per islet, as in $\mathrm{f}$. i: Small world-ness of a network calculated using global efficiency. 1000 random networks per islet were created to determine uncertainty of each data point (shown in black). j: Local efficiency. k: Average number of pixels between synchronized cells normalized to the average number of pixels between all cells in the Islet. $D<$ 1 indicates that cells preferentially synchronize to nearby cells. Significance in d-k determined by ordinary oneway ANOVA with Tukey multiple comparison test. Reported $\mathrm{P}$ values are adjusted. ${ }^{*} P \leq 0.05,{ }^{* *} P \leq 0.01$, $* * * P \leq 0.001$.

\section{Figure 7: Simulated islet functional network is influenced by changes in the structural network}

a: Representative cells within a simulated islet with high gap junction conductance $\left(g_{\text {coup }}=0.12 n S\right)$ (left) and within an islet with gap junction low conductance $\left(g_{\text {coup }}=0.03 n S\right)$ (right). Connections between a representative cell are shown with synchronized cell pairs in blue, gap junction cell pairs in red, and both in black. All data points represent the average statistic for each mouse. b: Venn diagrams of the probability of synchronization and probability of gap junction with the probability of both synchronization and gap junction as the overlapped area. c: Probability that two cells are synchronized given they share a gap junction connection. d: Probability that two cells were synchronized given they had similar rate of glucose metabolism and were within $15 \%$ of the islet from each other. e: Probability that two cells shared a gap junction connection given they were synchronized. f: Probability of similar rate of glucose metabolism given two cells were synchronized. g: Global efficiency for $0.12 n S, 0.06 n S$, and $0.03 n S$, for each islet seed. Overlaid is the box and whisker plot of 1000 random networks per simulated islet seed. $\mathbf{h}$ : Clustering coefficient for $0.12 n S, 0.06 n S$, and $0.03 n S$, for each islet seed. Overlaid is the box and whisker plot of 1000 random networks per simulated islet seed, as in $\mathrm{g}$. i: Small world-ness of a network calculated using global efficiency. 1000 random networks per islet were created to determine uncertainty of each data point (shown in black). j: Local efficiency for $0.12 n S, 0.06 n S$, and $0.03 n S$, for each islet seed. Shaded area in b is proportional to indicated probability. Statistical significance in c-j assessed by an ordinary one-way ANOVA with Tukey multiple comparison test. Reported $\mathrm{P}$ values are adjusted. ${ }^{*} P \leq$ $0.05,{ }^{* *} P \leq 0.01,{ }^{* * *} P \leq 0.001$. 


\section{Supplemental Figure Captions}

\section{Supplemental 1: Paths that maximized gap junction conductivity.}

a: Cumulative distribution functions of total conductance between two cells from 1-12 cells apart. Synchronized CDF is shown in blue, non-synchronized CDF is shown in green. $\mathbf{b}$ : Bar charts comparing the average conductance for synchronized and non-synchronized cells. $P$ values are not corrected, but significance (denoted by asterisks) is determined using a Bonferroni-corrected paired T-test. Since we there were 15 cell distances, we set the significance threshold $\alpha=0.003$.

\section{Supplemental 2: Paths that maximized metabolic rate.}

a: Cumulative distribution functions of total $\mathrm{k}_{\mathrm{glyc}}$ between two cells from 1-12 cells apart. Synchronized CDF is shown in blue, non-synchronized CDF is shown in green. b: Bar charts comparing the average conductance for synchronized and non-synchronized cells. P values are not corrected, but significance (denoted by asterisks) is determined using a Bonferroni-corrected paired T-test. Since we there were 15 cell distances, we set the significance threshold $\alpha=0.003$.

\section{Supplemental 3: Alternative Network Metrics for Calcium Islets from Cx36-KO mice}

a: Averaged degree distribution histograms for all Islets analyzed. Error bars indicate standard deviation. Purple (top) histogram shows the distribution of connections for wild type $\left({\left.\mathrm{C} \times 36^{+/+}\right)}\right)$islets. Orange (middle) shows the distribution of connections for heterozygous $\mathrm{C} \times 36$ knockout $\left(\mathrm{C} \times 36^{+-}\right)$islets. Blue (right) shows the distribution of connections for homozygous Cx36 knockout (Cx36-1-) islets. b: Average Pearson cross-correlation coefficient, between all cells in the islet. $\mathbf{d}$ : Number of cells in each islet. c: Small world calculated using path length instead of global efficiency). (Figure 7iSignificance, or lack thereof is determined by an ordinary one-way ANOVA. *P $\leq$ $0.05, * * P \leq 0.01$

\section{Supplemental 4: Network Metrics assessed by Islets}

This figure shows similar information as that of Figure 7, but the data points are individual islets and the bars are those Islets grouped by mouse. Genotypes from top to bottom: homozygous Cx36 knockout $\left(\mathrm{C} \times 36^{-/}\right)$islets, heterozygous $\mathrm{C} \times 36$ knockout $\left(\mathrm{C} \times 36^{+/-}\right)$islets, wild type $\left(\mathrm{C} \times 36^{+/+}\right)$islets. Random network distributions are overlayed as box-and-whisker plots.

\section{Supplemental 5: Network sensitivity to threshold}

a: Islet with representative cell connections calculated by a lower threshold ( $R_{t h}=0.999$ ) (right) and higher threshold ( $R_{t h}=0.99995$ ) (left). Synchronized cell pairs are shown in blue, gap junction pairs are shown in red and both are shown in black. $\mathbf{b}$ : Probability of a gap junction connection given synchronization for the five thresholds. c: Venn diagrams for the probability of synchronization (blue) and gap junction connection (red) with the overlapping area representing cell pairs that were both synchronized and gap junction coupled. 
bioRxiv preprint doi: https://doi.org/10.1101/2022.02.06.479331; this version posted February 9, 2022. The copyright holder for this preprint (which was not certified by peer review) is the author/funder. All rights reserved. No reuse allowed without permission.

\section{Tables}

\section{Table 1}

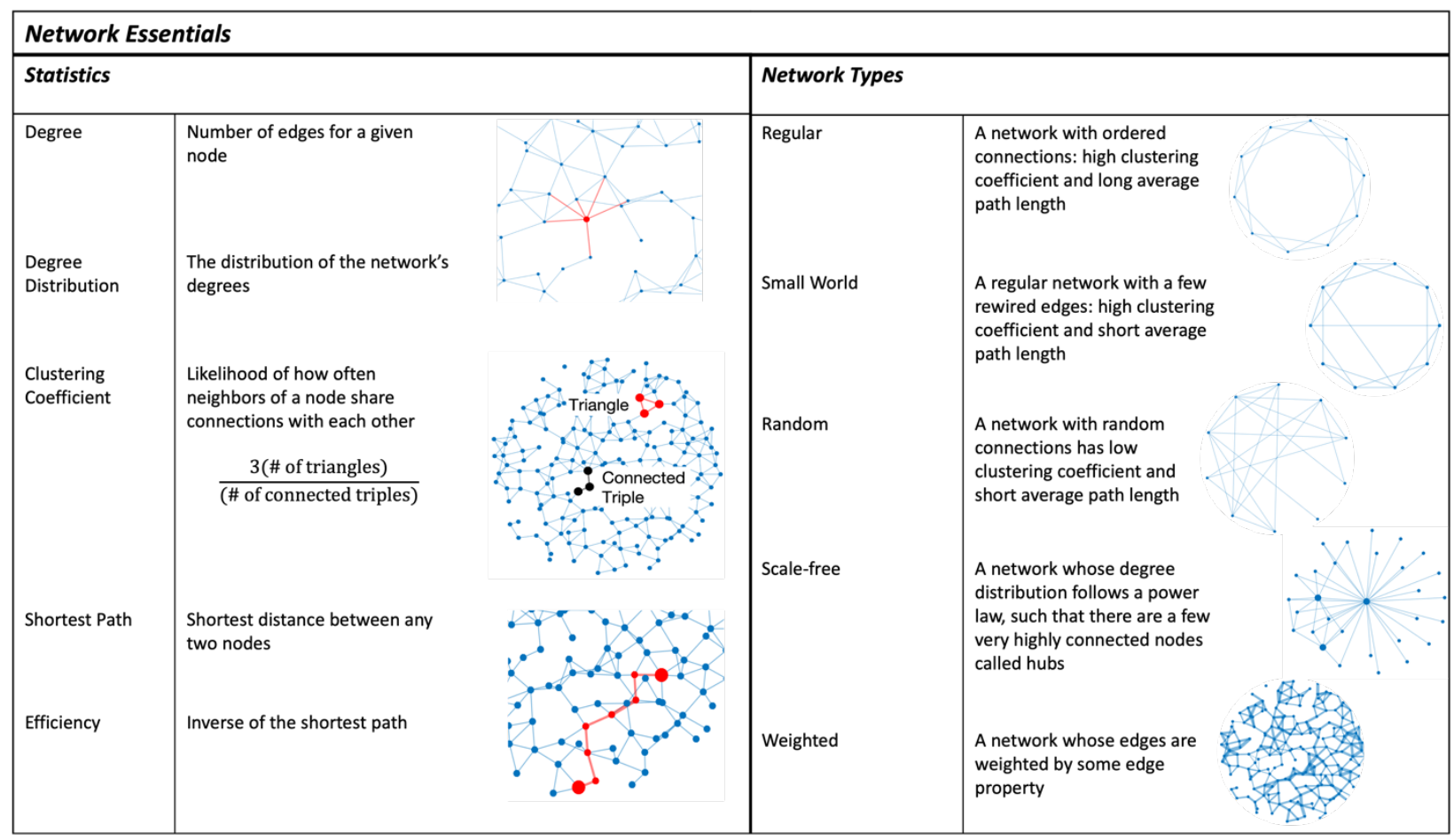




\section{Figures}

Figure 1

a
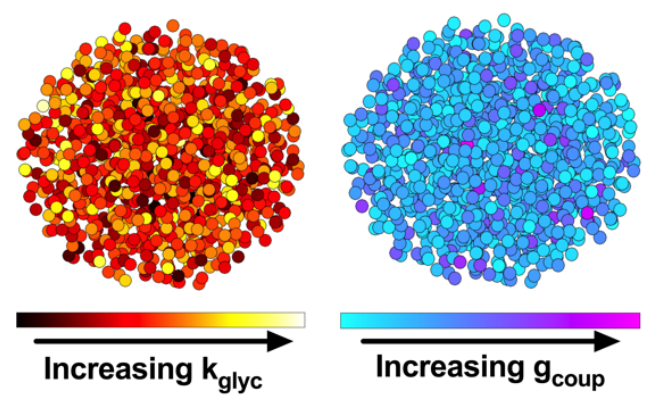

Functional Network

c

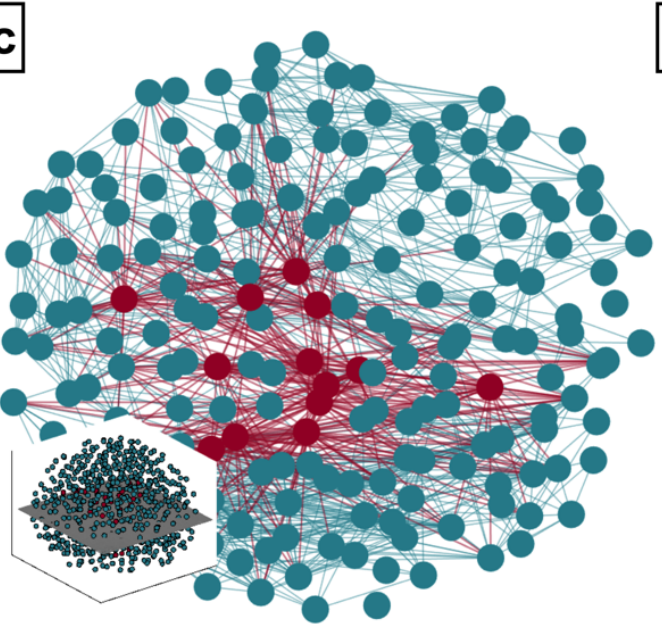

b

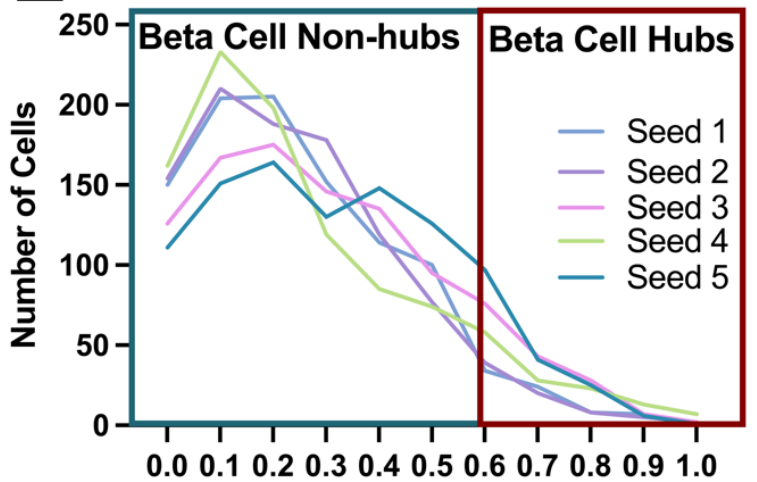

Bin Center
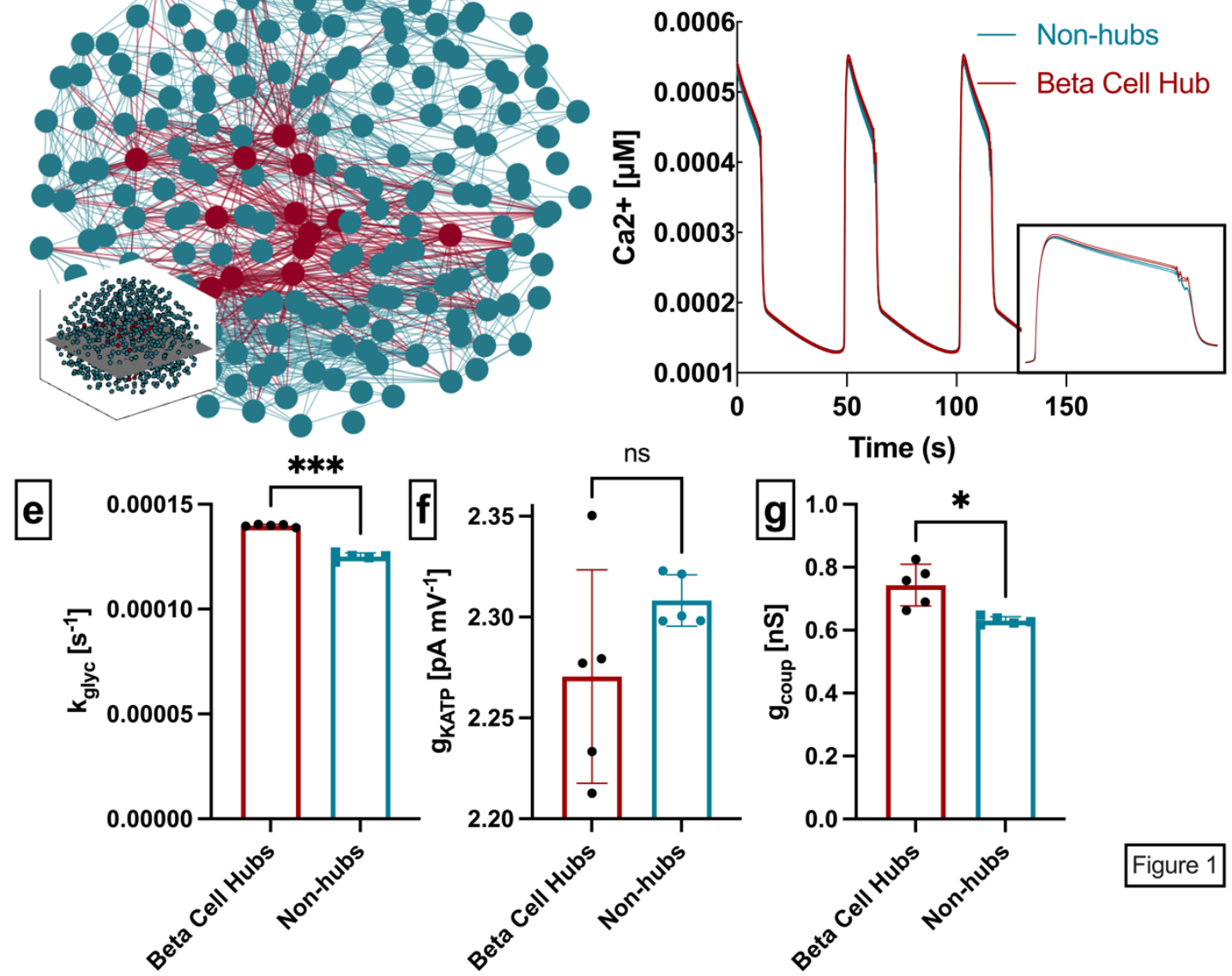

Time (s)

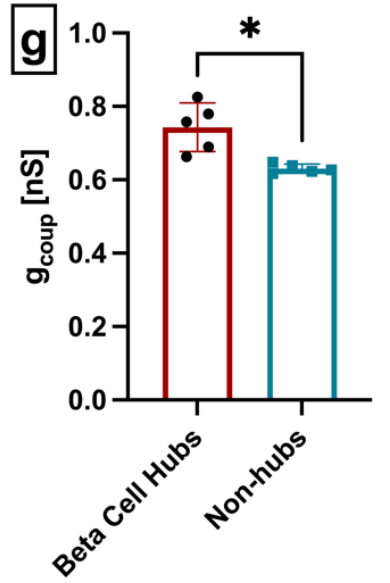

Figure 1 
bioRxiv preprint doi: https://doi.org/10.1101/2022.02.06.479331; this version posted February 9, 2022. The copyright holder for this preprint (which was not certified by peer review) is the author/funder. All rights reserved. No reuse allowed without permission.

Figure 2
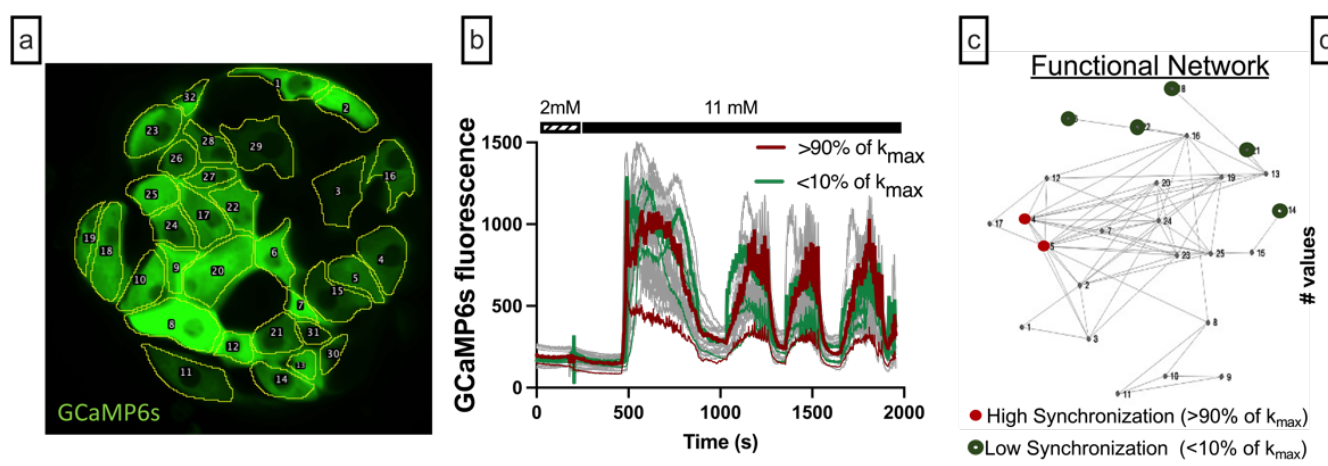

d
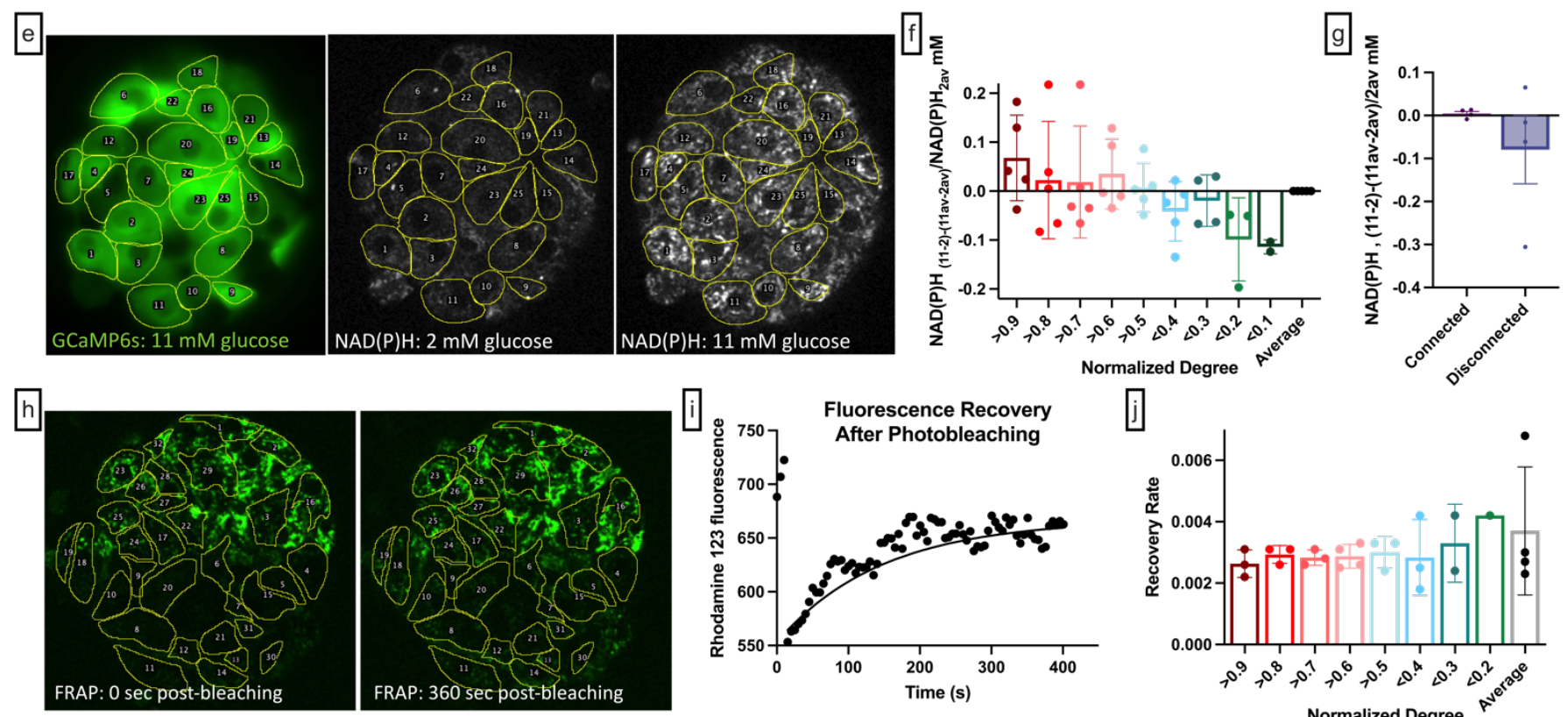

j]

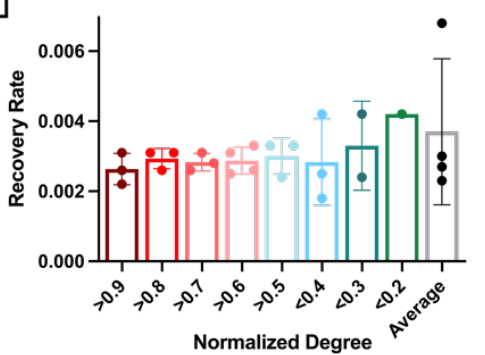

Figure 2 
bioRxiv preprint doa: https://doi.org/10.1101/2022.02.06.479331; this version posted February 9,2022 . The copyright holder for this preprint

(which was not certified by peer review) is the author/funder. All rights reserved. No reuse allowed without permission.

Figure 3

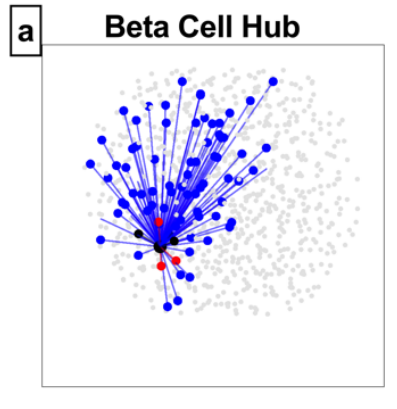

d

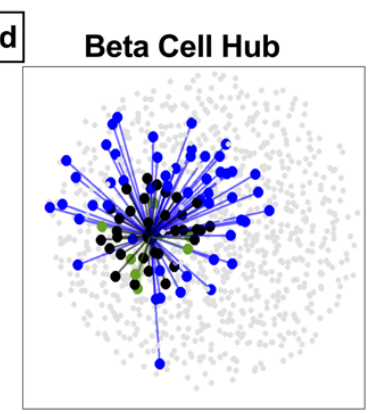

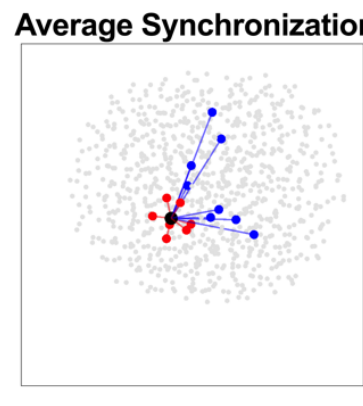

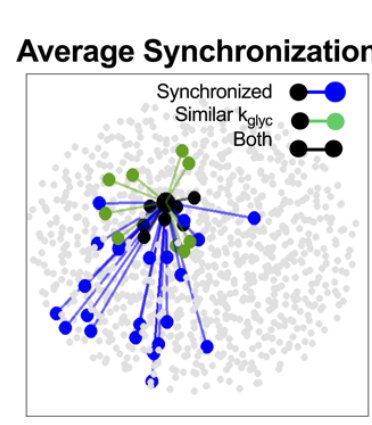

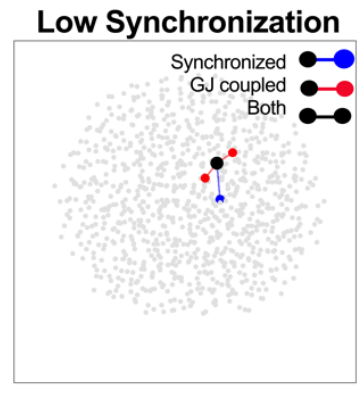
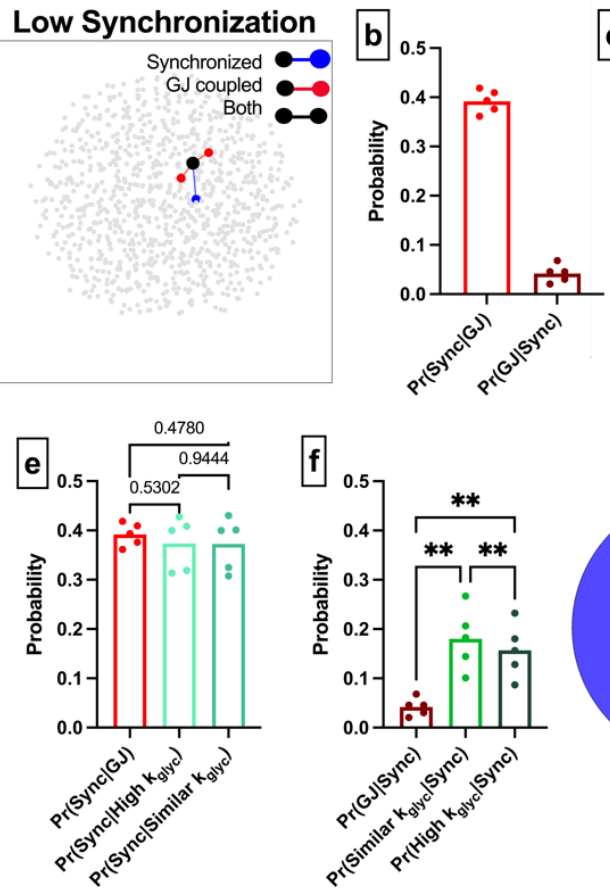

g
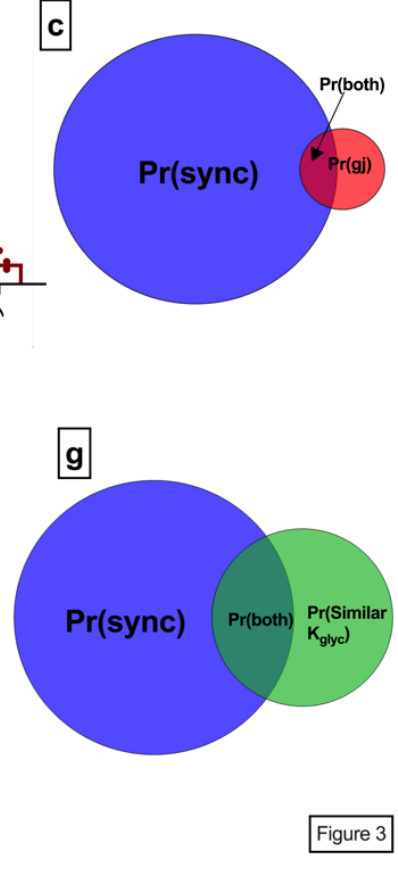
Figure 4

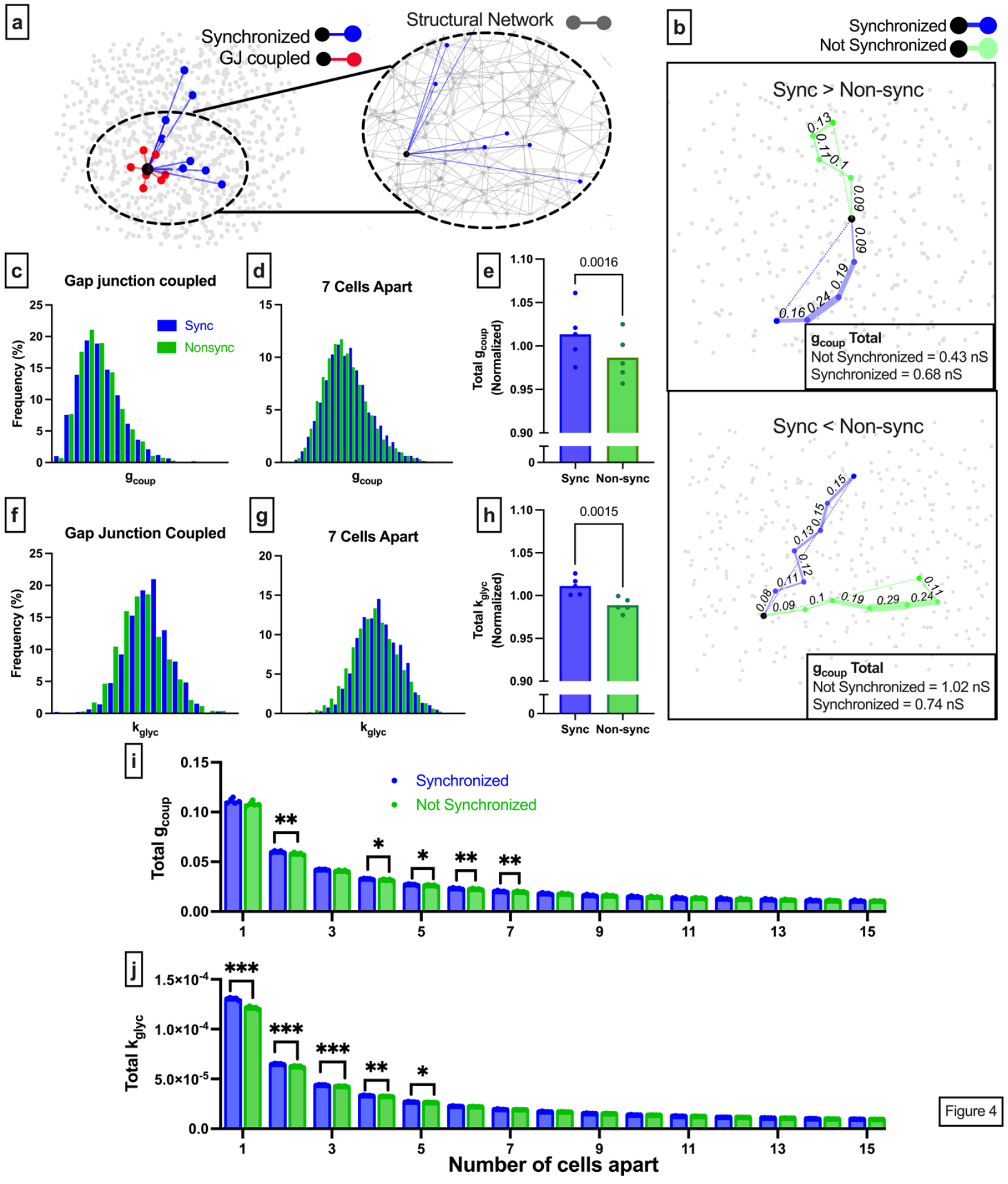


Figure 5
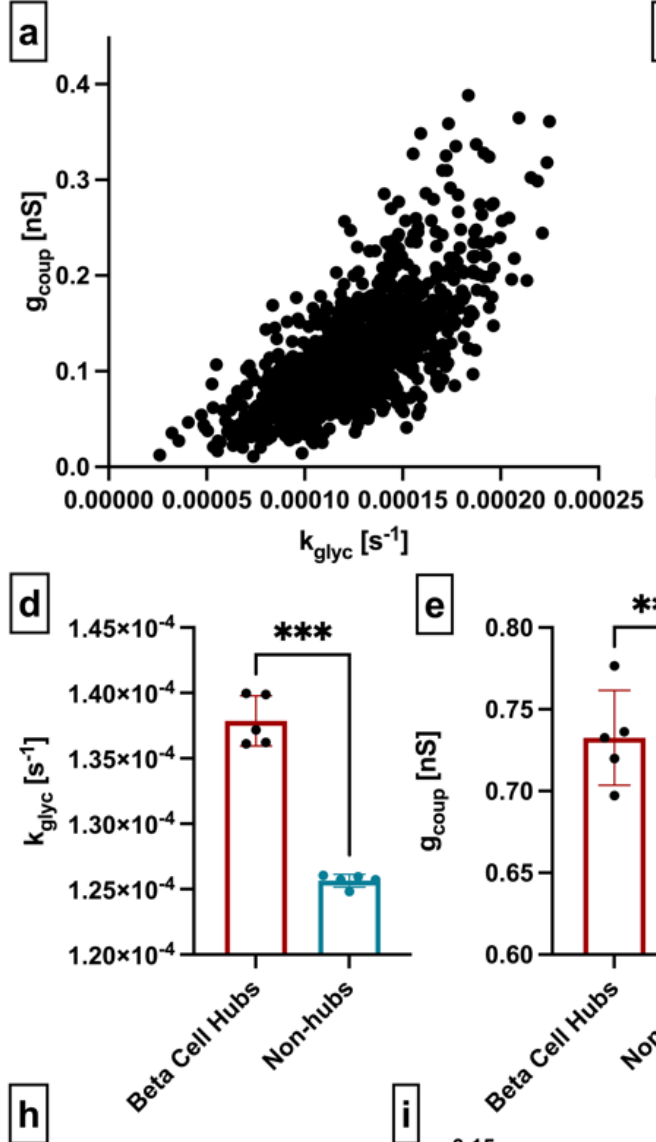

b

Functional Network

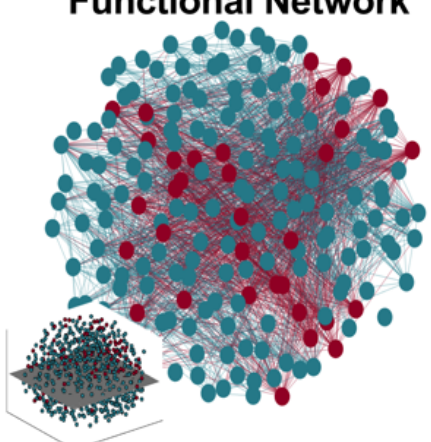

c

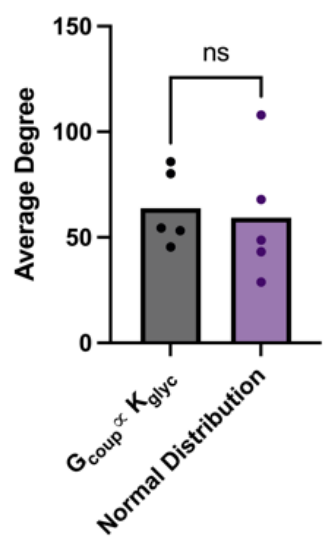

g

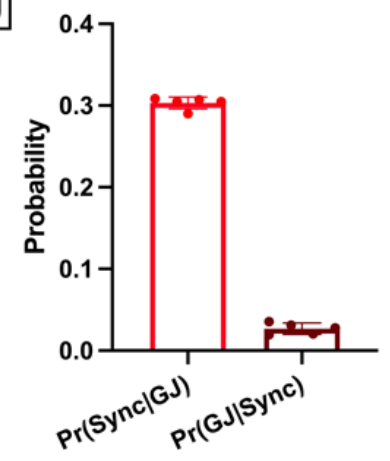

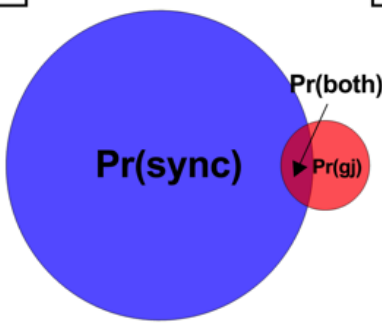

$0.157 * * *$

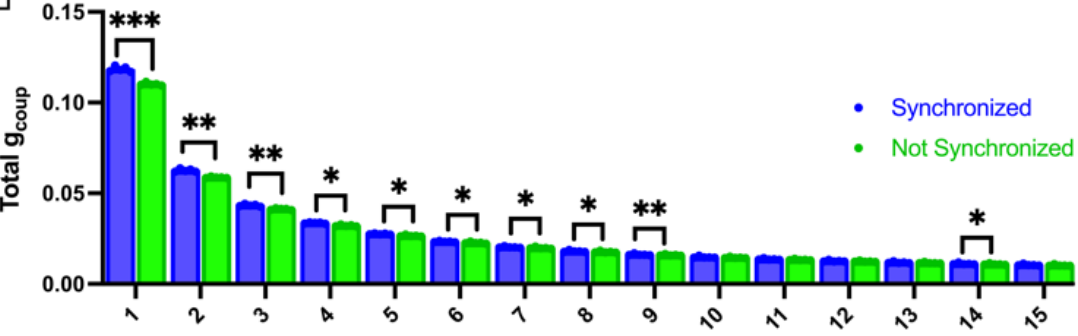

Figure 5 
bioRxiv preprint doi: https://doi.org/10.1101/2022.02.06.479331; this version posted February 9, 2022. The copyright holder for this preprint (which was not certified by peer review) is the author/funder. All rights reserved. No reuse allowed without permission.

Figure 6
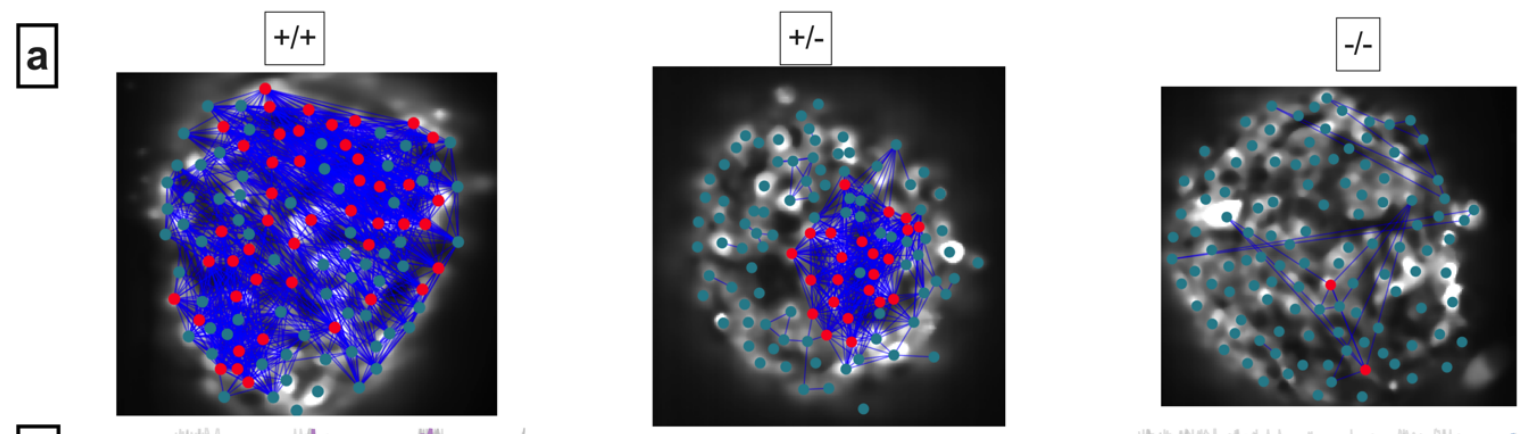

b
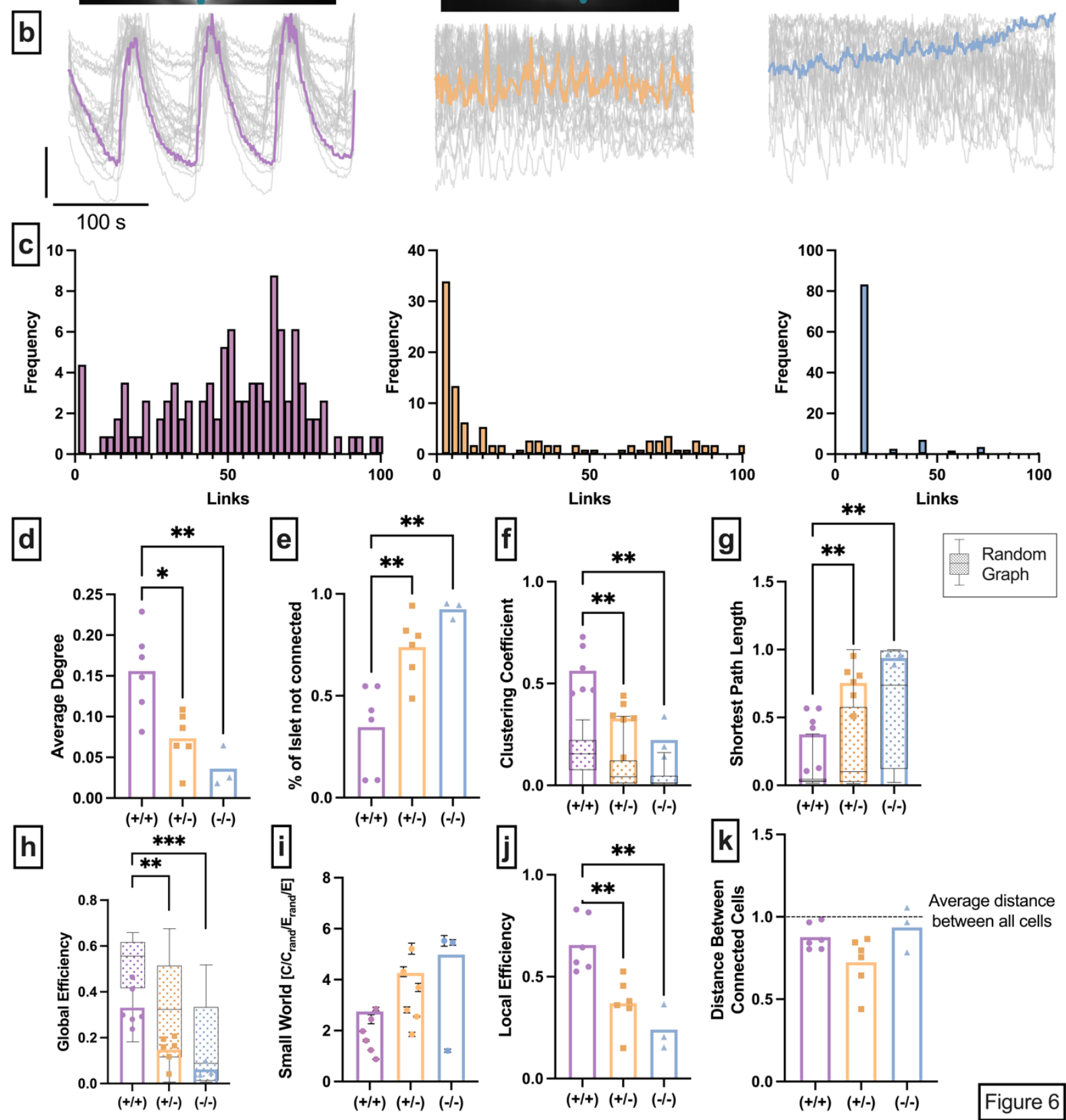
bioRxiv preprint doi: https://doi.org/10.1101/2022.02.06.479331; this version posted February 9, 2022. The copyright holder for this preprint (which was not certified by peer review) is the author/funder. All rights reserved. No reuse allowed without permission.

Figure 7
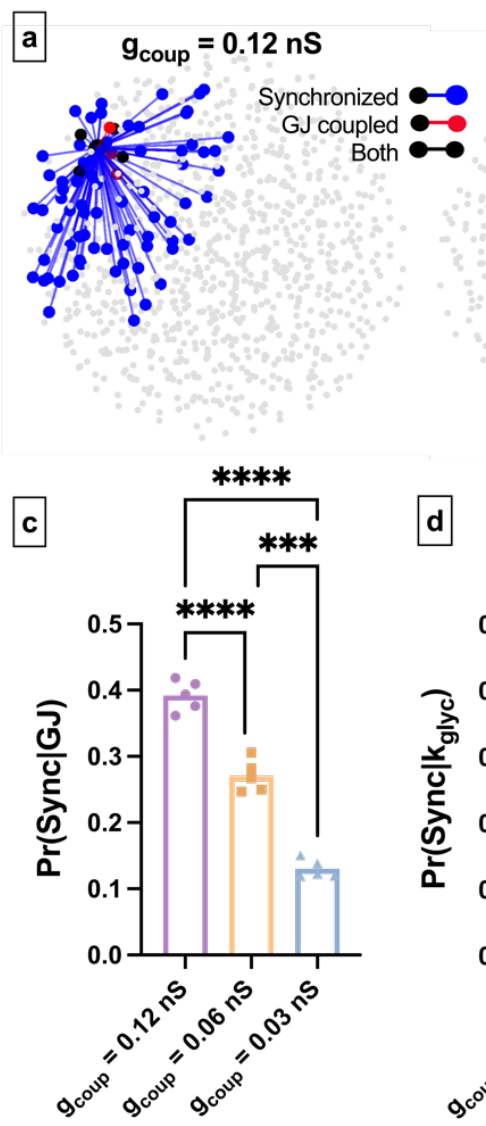

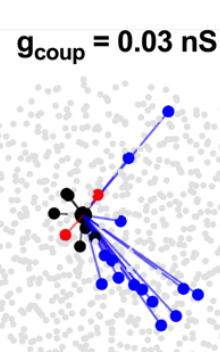

b

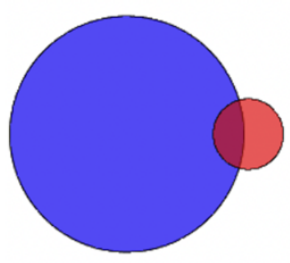

$\mathrm{g}_{\text {coup }}=.12 \mathrm{nS}$
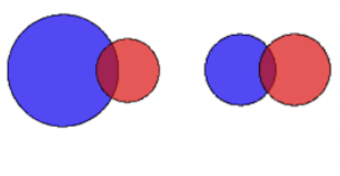

$.06 \mathrm{nS}$

$.03 \mathrm{nS}$
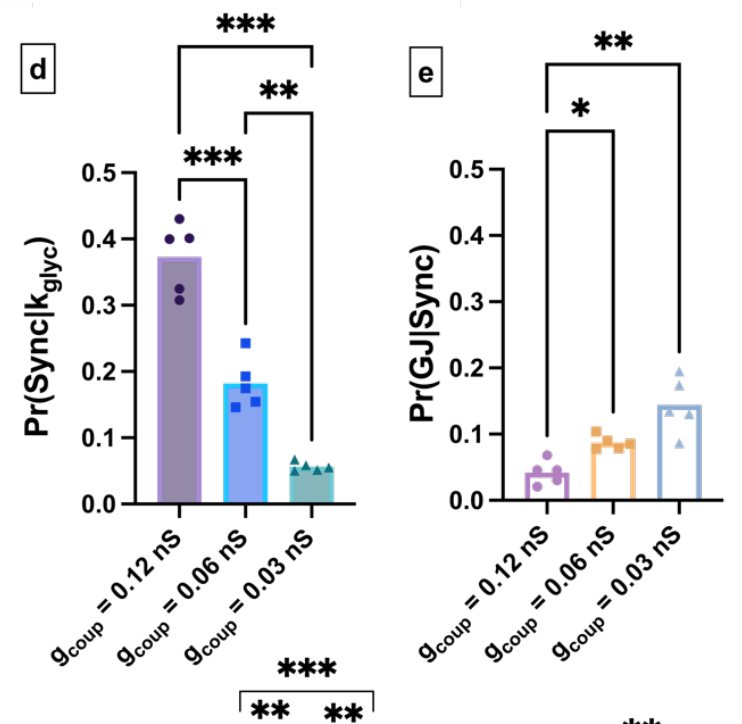

f
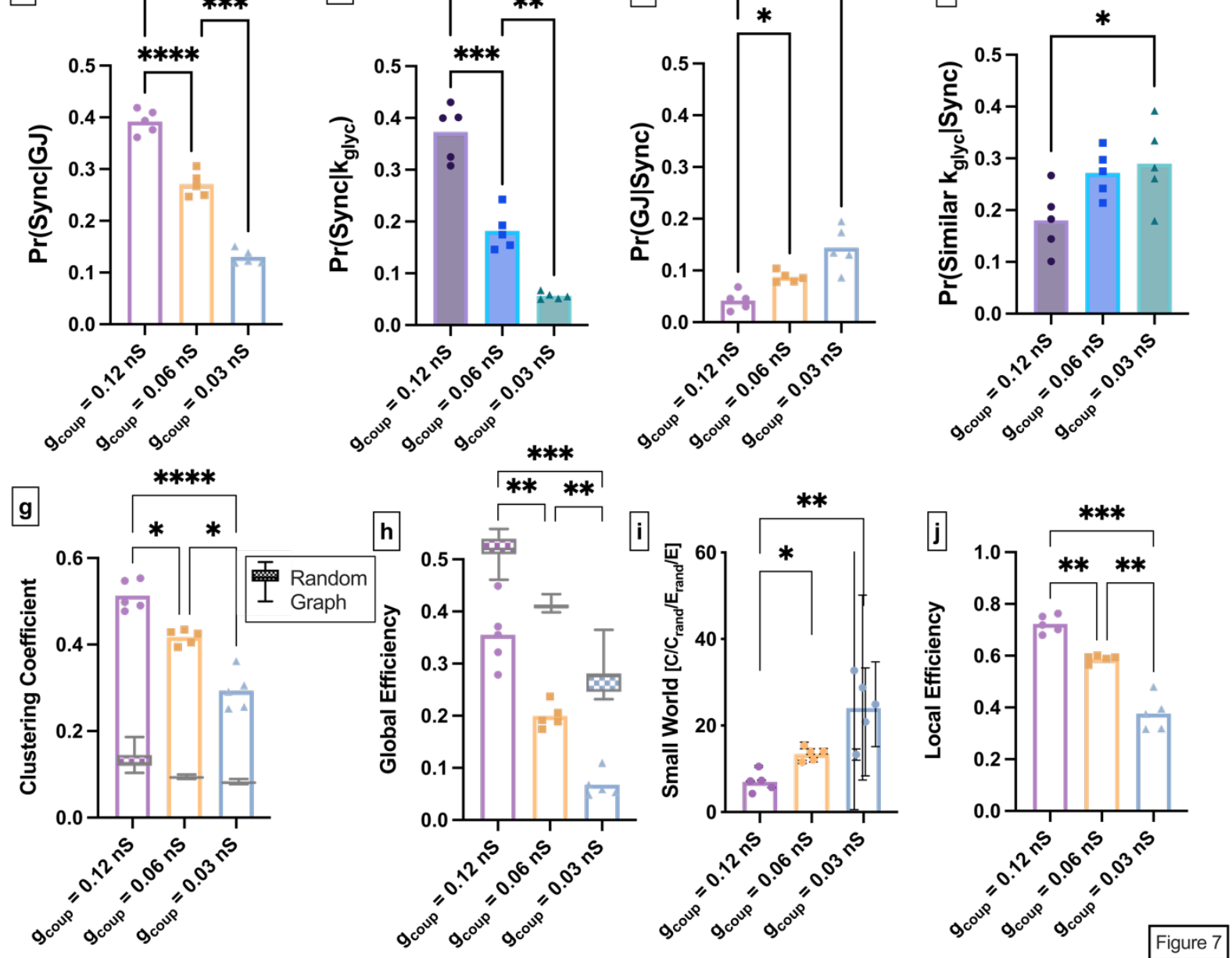


\section{Supplemental Figures}

\section{Supplemental 1}

\section{Total Gap Junction Conductance}
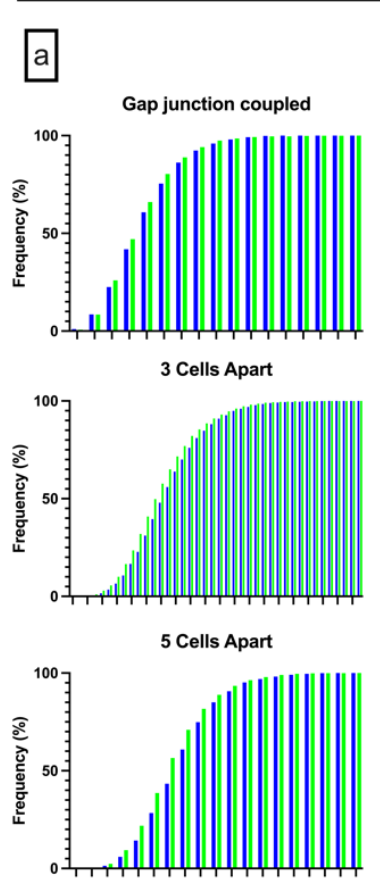

7 Cells Apart
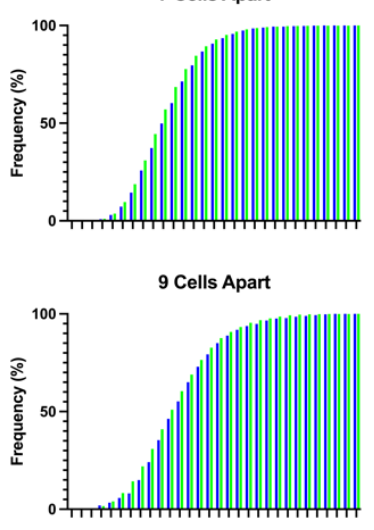

11 Cells Apart

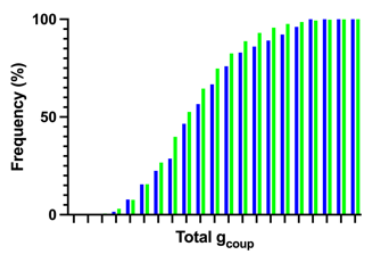

שSync

—Non Sync

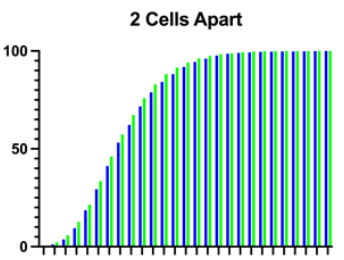

4 Cells Apart

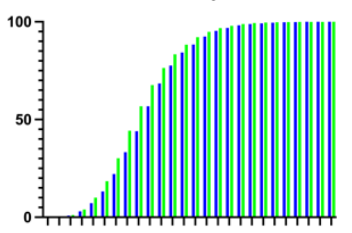

6 Cells Apart

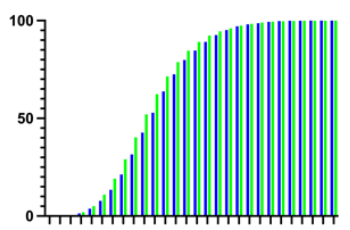

8 Cells Apart
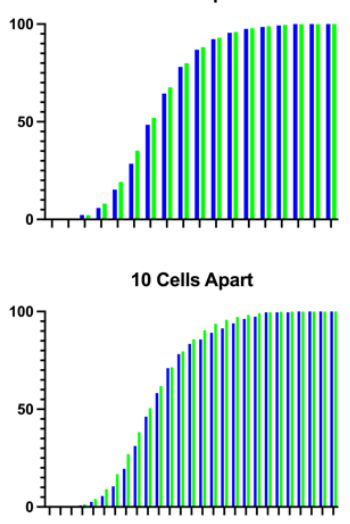

12 Cells Apart

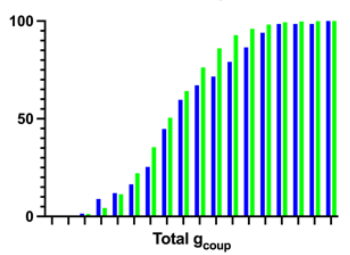

b
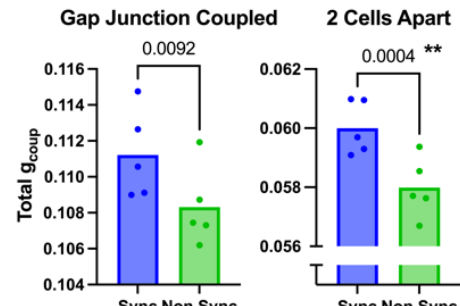

3 Cells Apart
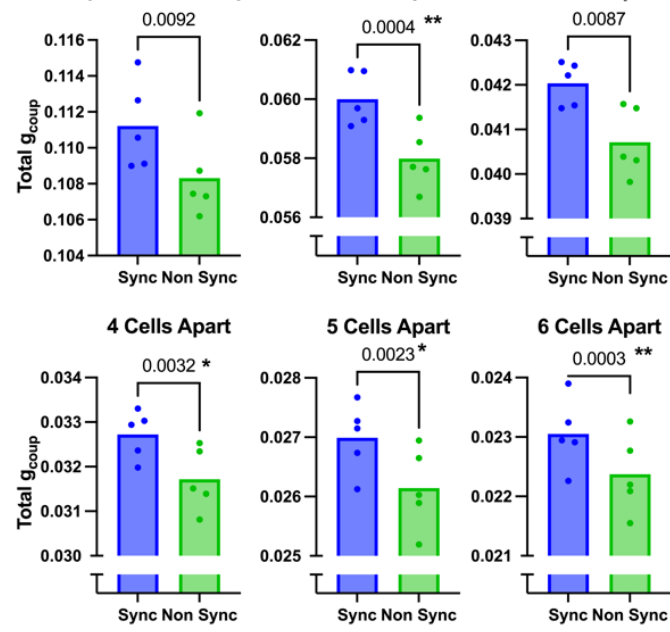

5 Cells Apart

Sync Non Sync

5 Cells Apart
0.028 .0023*

6 Cells Apart
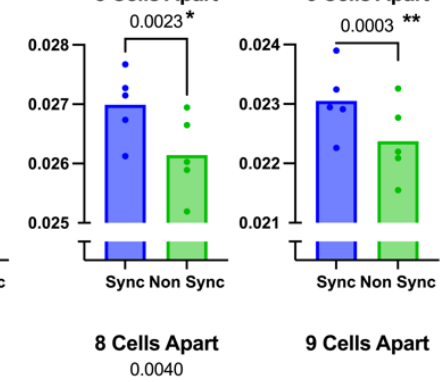

9 Cells Apart
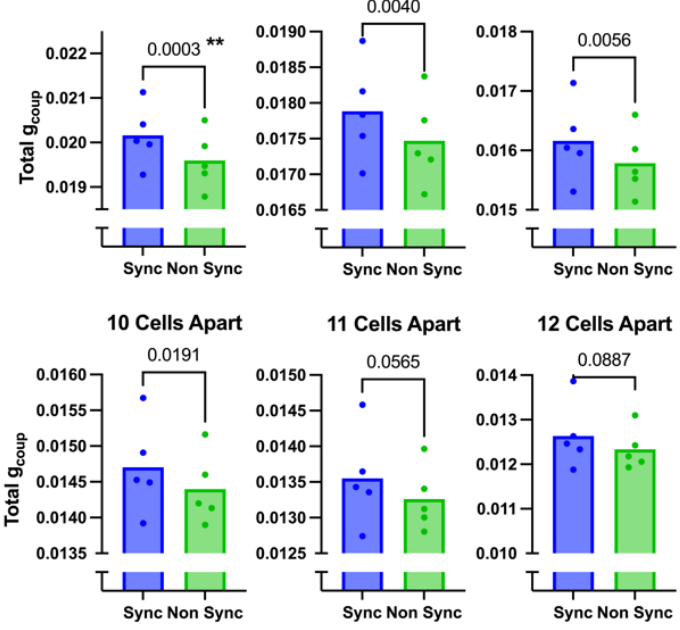

11 Cells Apart

12 Cells Apart

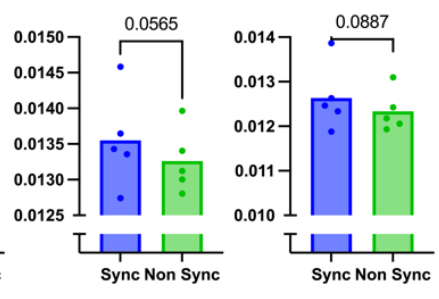

13 Cells Apart

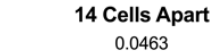

15 Cells Apart
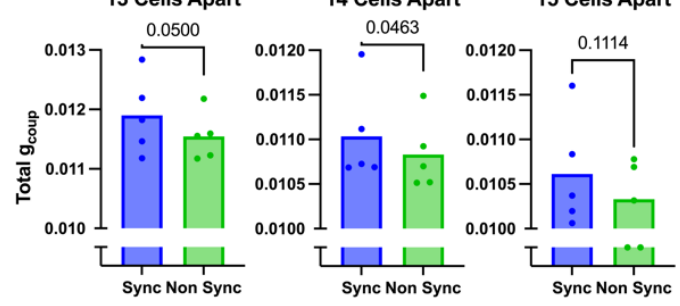

Supplemental 1 
bioRxiv preprint doi: https://doi.org/10.1101/2022.02.06.479331; this version posted February 9, 2022. The copyright holder for this preprint (which was not certified by peer review) is the author/funder. All rights reserved. No reuse allowed without permission.

Total $\mathrm{K}_{\text {glyc }}$
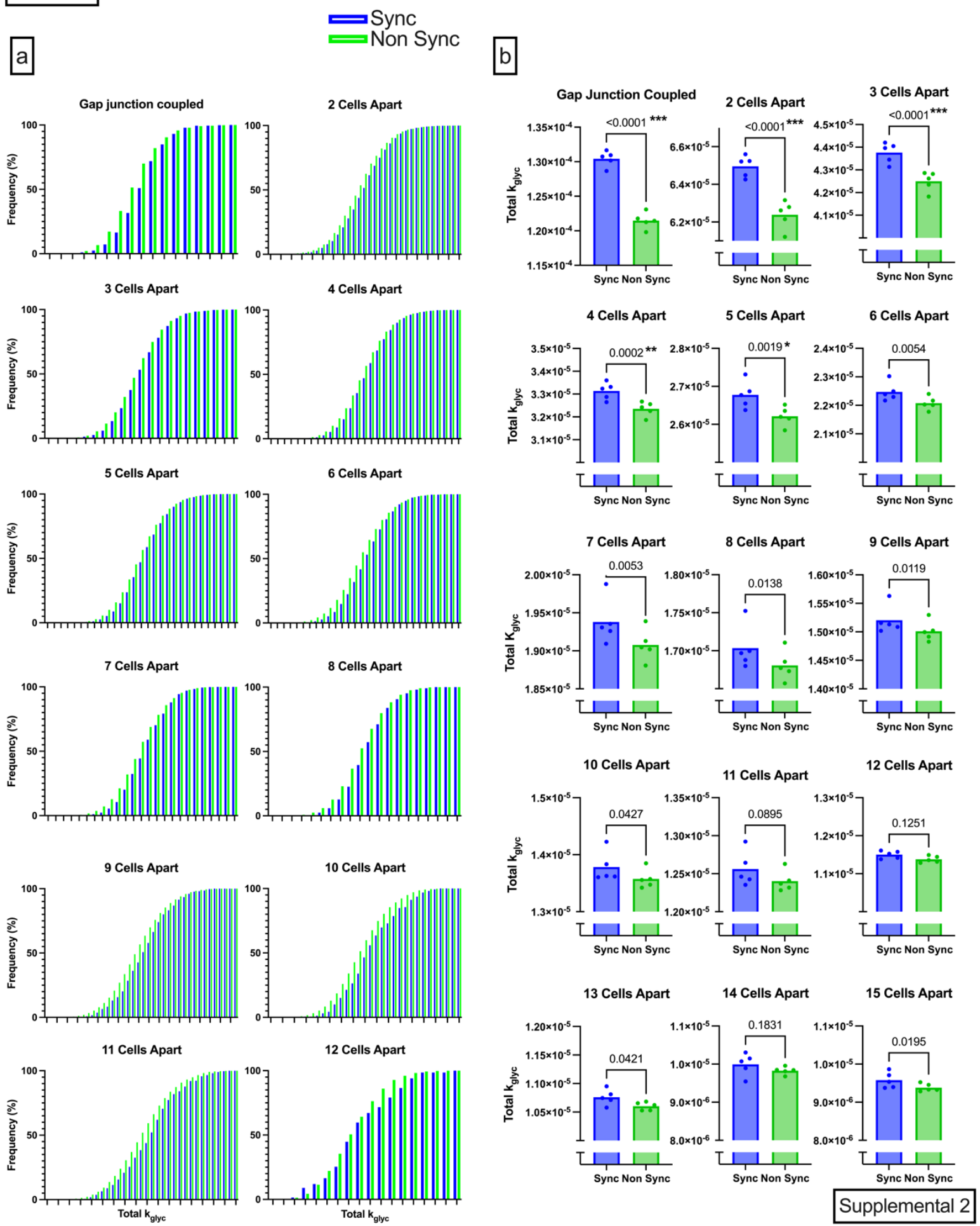

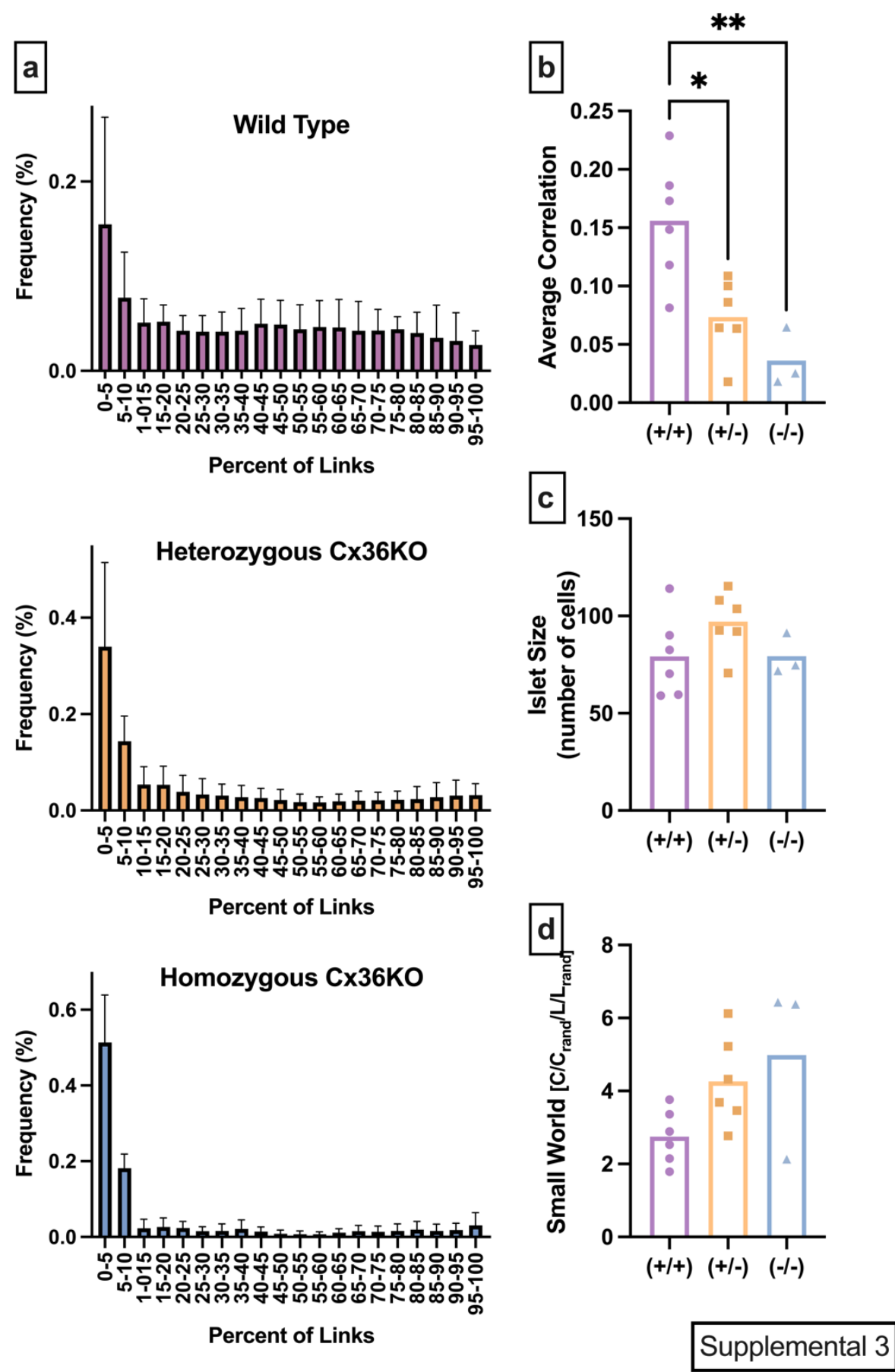


a Low Threshold $\left(R_{\mathrm{th}}=.999\right)$

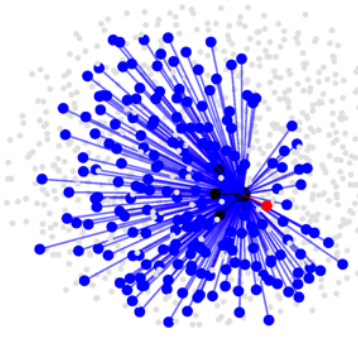

$\mathbf{C}$
High Threshold $\left(R_{\mathrm{th}}=.99995\right)$

Synchronized GJ coupled Both
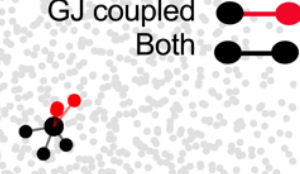

$\mathbf{R}_{\mathrm{th}}=.999$

$$
R_{\mathrm{th}}=.9995
$$
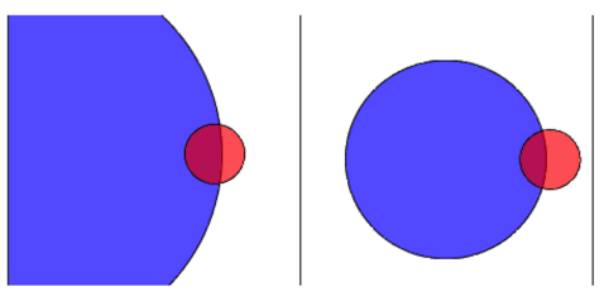

b

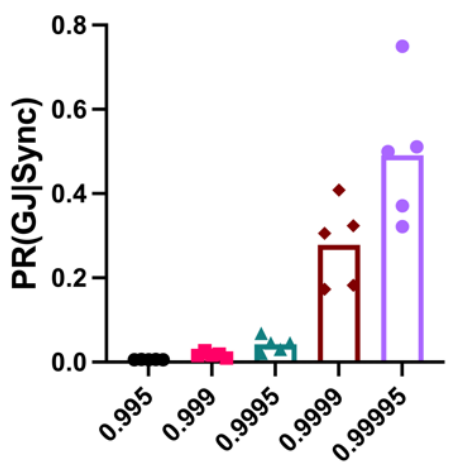

$\mathbf{R}_{\text {th }}$
$\mathbf{R}_{\mathrm{th}}=.9999$
$R_{\text {th }}=.99995$

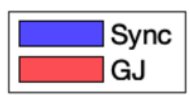

Supplemental 5 